\title{
Review Article \\ Recent Development of Graphene-Based Cathode Materials for Dye-Sensitized Solar Cells
}

\author{
Man-Ning Lu, ${ }^{1,2}$ Chin-Yu Chang, ${ }^{1}$ Tzu-Chien Wei, ${ }^{2}$ and Jeng-Yu Lin ${ }^{1}$ \\ ${ }^{1}$ Department of Chemical Engineering, Tatung University, No. 40, Section 3, Chung Shan North Road, Taipei City 104, Taiwan \\ ${ }^{2}$ Department of Chemical Engineering, National Tsing-Hua University, Hsinchu 300, Taiwan \\ Correspondence should be addressed to Jeng-Yu Lin; jylin@ttu.edu.tw
}

Received 10 December 2015; Accepted 13 March 2016

Academic Editor: Vincenzo Baglio

Copyright (c) 2016 Man-Ning Lu et al. This is an open access article distributed under the Creative Commons Attribution License, which permits unrestricted use, distribution, and reproduction in any medium, provided the original work is properly cited.

\begin{abstract}
Dye-sensitized solar cells (DSSCs) have attracted extensive attention for serving as potential low-cost alternatives to silicon-based solar cells. As a vital role of a typical DSSC, the counter electrode (CE) is generally employed to collect electrons via the external circuit and speed up the reduction reaction of $\mathrm{I}_{3}{ }^{-}$to $\mathrm{I}^{-}$in the redox electrolyte. The noble Pt is usually deposited on a conductive glass substrate as CE material due to its excellent electrical conductivity, electrocatalytic activity, and electrochemical stability. To achieve cost-efficient DSSCs, reasonable efforts have been made to explore Pt-free alternatives. Recently, the graphene-based CEs have been intensively investigated to replace the high-cost noble Pt CE. In this paper, we provided an overview of studies on the electrochemical and photovoltaic characteristics of graphene-based CEs, including graphene, graphene/Pt, graphene/carbon materials, graphene/conducting polymers, and graphene/inorganic compounds. We also summarize the design and advantages of each graphene-based material and provide the possible directions for designing new graphene-based catalysts in future research for high-performance and low-cost DSSCs.
\end{abstract}

\section{Introduction}

Nowadays, photovoltaic (PV) technology is considered as one of the widespread and efficient approaches to produce electricity from solar energy due to the increasing attention to low-carbon economy and renewable energy commercialization. On the basis of the basal technology, PV devices are generally classified as first-, second-, and third-generation solar cells. Since dye-sensitized solar cell (DSSC) was first reported in 1991 [1], it has been regarded as one of the promising third-regeneration solar cells due to low manufacturing cost, facile fabrication processes, relatively high power conversion efficiency (PCE), and wide spectral response in visible light region for indoor applications [2].

As illustrated in Figure 1, a typical DSSC basically contains a nanocrystalline semiconductor oxide, a dye sensitizer, an electrolyte redox couple, and a catalyst material as cathode, also called counter electrode (CE). To achieve high cell efficiency, the individual components in DSSCs are necessary to be optimized [3]. As a crucial component in DSSCs, the main functions of a $\mathrm{CE}$ is to transport electrons from external circuit and catalyze the reduction reaction of $\mathrm{I}_{3}{ }^{-}$to $\mathrm{I}^{-}$for dye regeneration. The overall $\mathrm{I}_{3}^{-}$reduction reaction occurring on the CE surface can be described in (1). Equation (1) can be divided into the following steps (as depicted in (2)-(5)) involved in the reduction mechanism of $\mathrm{I}_{3}^{-}$[4]:

$$
\begin{aligned}
\mathrm{I}_{3}^{-}+2 \mathrm{e}^{-} & \longleftrightarrow 3 \mathrm{I}^{-} \\
\mathrm{I}_{3}^{-} & \longleftrightarrow \mathrm{I}_{2}+\mathrm{I}^{-} \\
\mathrm{I}_{2}+2 \mathrm{CE} & \longleftrightarrow \mathrm{I}(\mathrm{CE})+\mathrm{I}(\mathrm{CE}) \\
\mathrm{I}(\mathrm{CE})+\mathrm{e}^{-} & \longleftrightarrow \mathrm{I}^{-}(\mathrm{CE}) \\
\mathrm{I}^{-}(\mathrm{CE}) & \longleftrightarrow \mathrm{I}^{-}+\mathrm{CE}
\end{aligned}
$$

Equation (2) represents the solution phase reaction, which has been verified to be relatively fast and considered to be in equilibrium [4]. Then $\mathrm{I}_{2}$ dissociates into two surface I atoms upon adsorption on the $\mathrm{CE}$ surface (designated as $\mathrm{I}(\mathrm{CE})$ ) via (3), and subsequently, I atoms on the CE surface are reduced to $\mathrm{I}^{-}$ions adsorbed on the $\mathrm{CE}$ surface through one-electron 


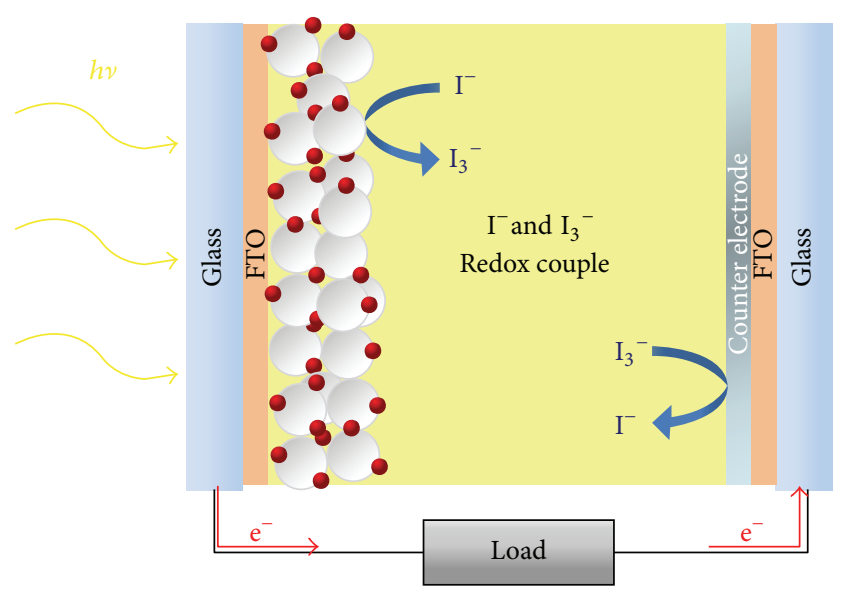

FIgURE 1: Schematic illustration of the operation principle of a DSSC.

transfer as depicted in (4). After that, the adsorbed $\mathrm{I}^{-}$ions are desorbed from the CE surface to be the solvated $\mathrm{I}^{-}$ions in electrolyte as illustrated in (5).

On the basis of the functions of a CE and the reduction mechanism of $\mathrm{I}_{3}{ }^{-}$, an efficient CE should exhibit both high electrical conductivity and electrocatalytic activity to keep a low overpotential and to minimize energy loss in DSSCs [5]. Generally, Pt has been proven to be an excellent CE material in DSSCs due to its high electrical conductivity and excellent electrocatalytic activity as well as great electrochemical stability. As a noble and sparse metal, however, the high cost of $\mathrm{Pt}$ (ca. $\$ 50,000 / \mathrm{Kg}$ ) restricts its practical applications. Therefore, much effort has been devoted to exploring the efficient Ptfree CEs. To date, a great deal of materials including carbon materials [6], conducting polymers [7-11], and inorganic materials [12-18] have been introduced as alternative $\mathrm{CE}$ materials to Pt.

Compared to other conventional carbon materials, graphene, a single-layer structure of two-dimensional graphite, possesses unique features of the strong mechanical strength, high electrical and thermal conductivity, large surface area, and high optical transmittance [19]. Therefore, it has been widely incorporated in the fields of microelectronic and optoelectronic devices, energy storage, and conversion materials $[20,21]$. Since Aksay's group revealed the functional graphene sheets (FGSs) as CE material for efficiently catalyzing the redox reaction of $\mathrm{I}_{3}{ }^{-} / \mathrm{I}^{-}$in 2010 , a variety of graphene-based CE materials have been intensively developed for Pt-free DSSCs [22].

In this work, we comprehensively reviewed the advance of research on graphene-based CE materials for Pt-free DSSCs, with emphasis on composite materials.

\section{Graphene CEs}

Graphene has been considered as one of the promising Ptfree CE alternatives in DSSCs due to its specific properties of high electrical conductivity, excellent electrocatalytic activity, great anticorrosion resistance, and larger surface area [24,
28]. In general, graphene materials can be synthesized via mechanical exfoliation, epitaxial growth, chemical vapor deposition, thermal exfoliation [29-32], and so forth. Table 1 summarizes the comparison of various graphene CEs in DSSCs. For example, Aksay's group used thermal exfoliation to synthesize FGSs with defects and oxygen-containing function groups (hydroxyl, carbonyl, and epoxide) [24]. They found that the increase in $\mathrm{C} / \mathrm{O}$ ratio of FGSs is positively associated with their electrocatalytic activity. Nevertheless, the electrical conductivity of FGSs can be reduced by forming more functional groups while the temperature of thermal processing increases over $1500^{\circ} \mathrm{C}$. After the optimization of $\mathrm{C} / \mathrm{O}$ ratio in FGSs, the FGSs-based DSSC reached higher PCE of $5.48 \%$ and fill factor (FF) of 0.60 than Pt-based DSSC (4.99\% and 0.57). They found that the improved FF value of the FGSs-based DSSC can be attributed to its relatively low charge-transfer resistance $\left(R_{\mathrm{ct}}\right)$ of $0.64 \Omega \mathrm{cm}^{2}$, which is even lower than that of the Pt CE $\left(0.79 \Omega \mathrm{cm}^{2}\right)$. Grätzel's group prepared an optically transparent graphene thin film by dropping commercial graphene nanoplatelets on fluorine doped tin oxide (FTO) glass substrates [23]. They found that the graphene $\mathrm{CE}$ has a much lower $R_{\mathrm{ct}}$ value in an ionic liquid than in the traditional organic solvent by a factor of $5-6$, suggesting that the regeneration of $\mathrm{I}_{3}{ }^{-} / \mathrm{I}^{-}$in an ionic liquid is superior to that in the traditional organic solvent (as depicted in Figure 2). Choi et al. [33] further prepared graphene CEs using electrophoretic deposition followed by annealing treatment at $200 \sim 600^{\circ} \mathrm{C}$. They found that the DSSC using the graphene CEs obtained after the annealing treatment at $600^{\circ} \mathrm{C}$ exhibited the optimized PCE of $5.69 \%$. Kaniyoor and Ramaprabhu [34] synthesized graphene with defectrich and wrinkled structure through a thermally exfoliated method. Then, the thermally exfoliated graphene (TEG) was suspended in Nafion/ethanol solution and subsequently dropped on FTO glass substrates to form the TEG CEs. The TEG CE demonstrated $R_{\mathrm{ct}}$ value of $11.7 \Omega \mathrm{cm}^{2}$, which is close to that of the Pt CE $\left(6.5 \Omega \mathrm{cm}^{2}\right)$. This indicates that the wrinkled and defect-rich structure of TEG can provide large surface area and high density of defect sides for $\mathrm{I}_{3}{ }^{-} / \mathrm{I}^{-}$reduction reaction and thus the electron transfer kinetics at the CE/electrolyte interface is promoted. Zhang et al. synthesized novel 3D structure of graphene nanosheets (GNs) as CE material for DSSCs [28]. The GN was prepared using oxidative exfoliation of graphite followed by hydrazine reduction and annealing process. After the optimization of annealing temperature, it can be found that the DSSC assembled with the GN CE annealed at $400^{\circ} \mathrm{C}$ exhibited the best cell performance of $6.81 \%$, which is comparable to that of the Pt-based DSSC (7.59\%). After being annealed at $400^{\circ} \mathrm{C}$, the $\mathrm{GN}$ was revealed with a unique $3 \mathrm{D}$ structure. This signifies that the annealed GN can afford sufficient surface area for $\mathrm{I}_{3}^{-} / \mathrm{I}^{-}$reduction reaction and therefore its $R_{\mathrm{ct}}$ value is significantly decreased from 337.2 to $1.2 \Omega$.

On the other hand, $\mathrm{Xu}$ et al. [41] reported a facile and rapid microwave-assisted method to synthesize hemin functionalized reduced graphene oxide (hemin-RGO). It was found that 5-layer hemin-RGO demonstrated $R_{\mathrm{ct}}$ value of ca. $7 \Omega$, comparable to that of the Pt-based CE $(7 \Omega)$. Lee et 
TABLE 1: Photovoltaic performance of the DSSCs assembled with various graphene CEs.

\begin{tabular}{|c|c|c|c|c|c|c|c|c|}
\hline $\mathrm{CE}$ & Substrate & Preparation method & Redox couple & Dye & $R_{\mathrm{ct}}\left(\Omega \mathrm{cm}^{2}\right)$ & $\mathrm{FF}$ & PCE (\%) & Ref \\
\hline GO-GNP & FTO glass & Drop-casting & $\mathrm{I}^{-} / \mathrm{I}_{3}^{-}$ & N3 & 0.64 & 0.60 & 4.99 & {$[20]$} \\
\hline GNP & FTO glass & Drop-casting & $\mathrm{I}^{-} / \mathrm{I}_{3}^{-}$ & N719 & 0.40 & 0.74 & 6.89 & [29] \\
\hline RGO & FTO glass & Electrophoretic deposition & $\mathrm{I}^{-} / \mathrm{I}_{3}^{-}$ & N719 & $38.00^{*}$ & 0.65 & 5.69 & {$[46]$} \\
\hline TEG & FTO glass & Drop-casting & $\mathrm{I}^{-} / \mathrm{I}_{3}^{-}$ & N719 & 11.70 & 0.54 & 2.82 & [30] \\
\hline Hemin-RGO & FTO glass & Drop-casting & $\mathrm{I}^{-} / \mathrm{I}_{3}^{-}$ & N719 & 6.12 & 0.31 & 2.45 & [31] \\
\hline RGO & FTO glass & Screen-printing & $\mathrm{I}^{-} / \mathrm{I}_{3}^{-}$ & N719 & 1.20 & 0.54 & 6.81 & [19] \\
\hline RGO & ITO glass & Spin-coating & $\mathrm{I}^{-} / \mathrm{I}_{3}^{-}$ & N719 & 21.50 & 0.56 & 2.13 & [47] \\
\hline 3D-NFG & FTO glass & CVD & $\mathrm{I}^{-} / \mathrm{I}_{3}^{-}$ & N719 & 45.88 & 0.60 & 5.20 & {$[32]$} \\
\hline VG & FTO glass & CVD & $\mathrm{I}^{-} / \mathrm{I}_{3}^{-}$ & N719 & 0.0073 & 0.67 & 5.36 & {$[23]$} \\
\hline $\begin{array}{l}\text { Honeycomb-like } \\
\text { structure graphene }\end{array}$ & FTO glass & CVD & $\mathrm{I}^{-} / \mathrm{I}_{3}^{-}$ & N719 & $20.00^{*}$ & 0.37 & 7.80 & {$[34]$} \\
\hline $\mathrm{N}$-doped graphene & FTO glass & CVD & $\mathrm{I}^{-} / \mathrm{I}_{3}^{-}$ & N719 & - & 0.33 & 3.12 & [41] \\
\hline GNP & FTO glass & Drop-casting & $\mathrm{Co}^{3+} / \mathrm{Co}^{2+}$ & Y123 & $3.50^{*}$ & 0.70 & 9.30 & {$[45]$} \\
\hline GNP & FTO glass & Drop-casting & $\mathrm{Co}^{3+} / \mathrm{Co}^{2+}$ & Y123 & 3.30 & 0.72 & 9.40 & [48] \\
\hline FGS & FTO glass & Screen-printing & $\mathrm{I}^{-} / \mathrm{I}_{3}^{-}$ & N719 & - & 0.67 & 6.79 & [20] \\
\hline FGS & FTO glass & Screen-printing & $\mathrm{Co}^{3+} / \mathrm{Co}^{2+}$ & D35 & - & 0.65 & 4.51 & [20] \\
\hline FGS & FTO glass & Screen-printing & $\mathrm{S}^{3+} / \mathrm{S}^{2+}$ & D35 & - & 0.55 & 3.45 & [20] \\
\hline RGO & FTO glass & Drop-casting & $\mathrm{Co}^{3+} / \mathrm{Co}^{2+}$ & T123 & 1.27 & 0.67 & 9.30 & [49] \\
\hline $\mathrm{N}$-doped graphene & FTO glass & Drop-casting & $\mathrm{Co}^{3+} / \mathrm{Co}^{2+}$ & YD-2-o-C8 & 1.38 & 0.72 & 8.3 & {$[50]$} \\
\hline
\end{tabular}

${ }^{*}$ Represents that the unit of the $R_{\mathrm{ct}}$ value is $\Omega$.

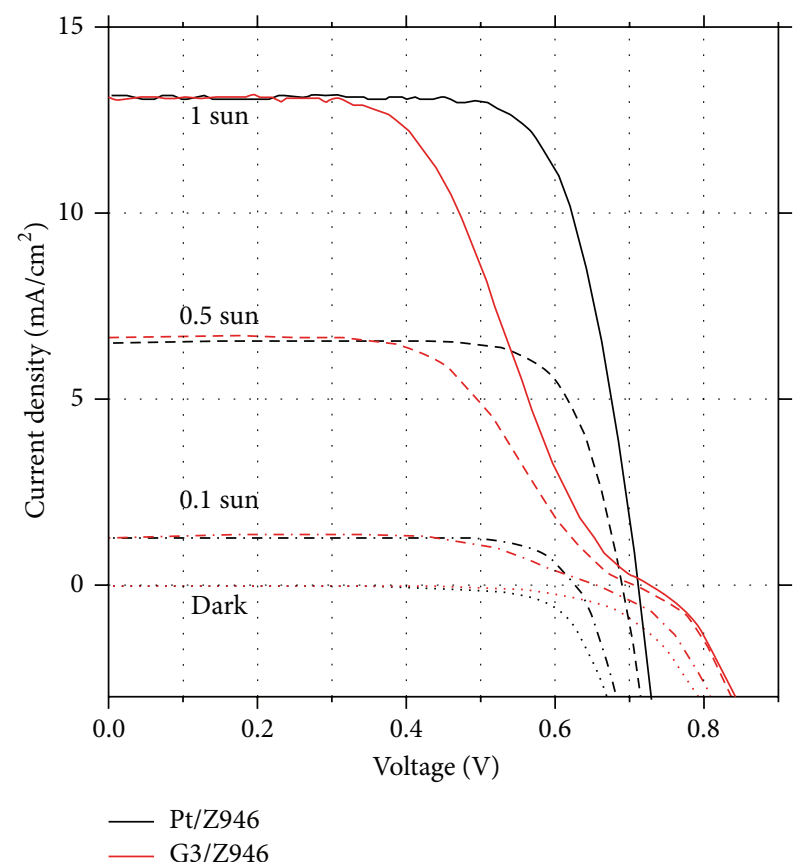

(a)

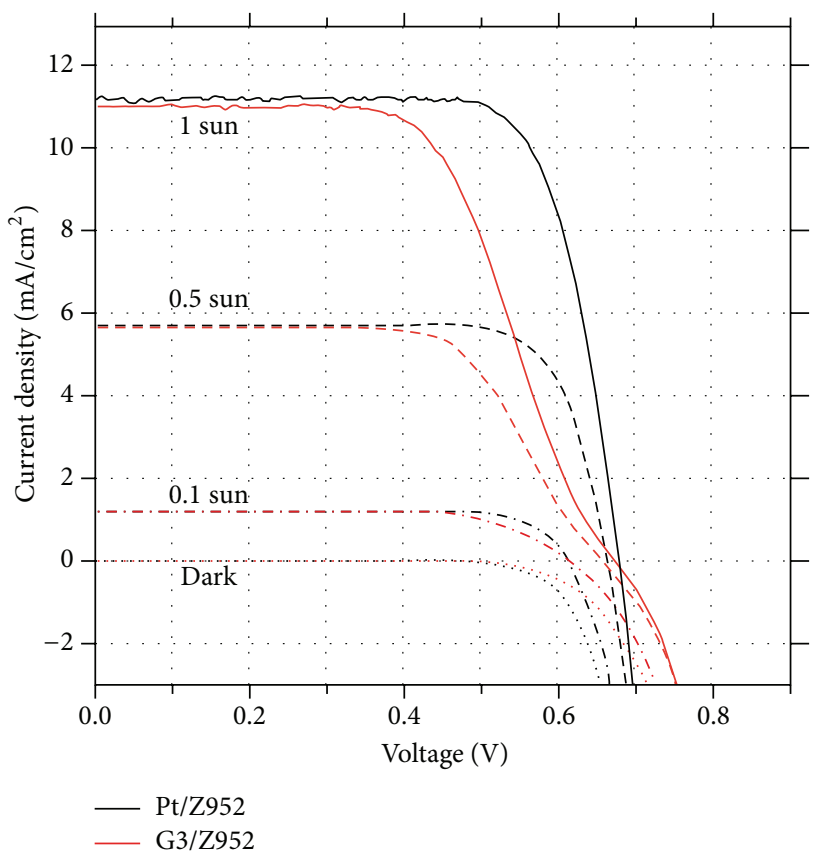

(b)

FIGURE 2: Current-voltage characteristics of a dye-sensitized solar cell with the platinized FTO (black lines) or G3 cathode (red lines) under various light intensities. (a) Z946 electrolyte. (b) Z952 electrolyte [23].

al. fabricated 3D nanofoam of few-layer graphene (3D-NFG) with large-area coverage via the chemical vapor deposition (CVD) technique [42]. The PCE of the DSSC based on the $3 \mathrm{D}-\mathrm{NFG}$ CE reached 5.2\%, which was even close to that of Pt CE (5.7\%). Yu et al. prepared the vertically oriented graphene (VG) nanosheets by plasma-enhanced chemical vapor deposition (PECVD), and the as-synthesized VG was found to be with large surface area and abundant oxygen functional groups [43]. According to series of electrochemical characterizations including electrochemical impedance 
TABLE 2: Photovoltaic performance of the DSSC using various Pt/graphene composite CEs.

\begin{tabular}{|c|c|c|c|c|c|c|c|c|}
\hline $\mathrm{CE}$ & Substrate & Preparation method & Redox couple & Dye & $R_{\mathrm{ct}}\left(\Omega \mathrm{cm}^{2}\right)$ & FF & PCE (\%) & Ref \\
\hline $\begin{array}{l}\text { Pt NPs/graphene } \\
\text { sheet }\end{array}$ & FTO glass & Electrodeposition & $\mathrm{I}^{-} / \mathrm{I}_{3}^{-}$ & N3 & 2.36 & 0.59 & 2.91 & [33] \\
\hline $\mathrm{Pt} / \mathrm{RGO}$ & FTO glass & Two-step reduction & $\mathrm{I}^{-} / \mathrm{I}_{3}^{-}$ & N719 & 34.95 & 0.60 & 4.01 & {$[51]$} \\
\hline PtNP/GR & FTO glass & Water-ethylene method & $\mathrm{I}^{-} / \mathrm{I}_{3}^{-}$ & N719 & $10.45^{*}$ & 0.67 & 6.35 & {$[52]$} \\
\hline GNS/Pt-NHB & FTO glass & Electrospray & $\mathrm{I}^{-} / \mathrm{I}_{3}^{-}$ & N719 & 27.00 & 0.66 & 7.97 & [53] \\
\hline Pt-NPs/RGO & FTO glass & Dry-plasma reduction & $\mathrm{I}^{-} / \mathrm{I}_{3}^{-}$ & N719 & 0.62 & 0.67 & 8.56 & [54] \\
\hline GNS/Pt & FTO glass & Electrostatic Layer-by-layer self-assembly & $\mathrm{I}^{-} / \mathrm{I}_{3}^{-}$ & N719 & 30.80 & 0.73 & 6.09 & [55] \\
\hline $\mathrm{PtNP} / \mathrm{GN}$ & FTO glass & Electrodeposition & $\mathrm{I}^{-} / \mathrm{I}_{3}^{-}$ & N719 & 2.08 & 0.68 & 7.88 & [56] \\
\hline GN/PtNPs & FTO glass & Polyol reduction & $\mathrm{I}^{-} / \mathrm{I}_{3}^{-}$ & N719 & 2.55 & 0.70 & 8.79 & [57] \\
\hline $\mathrm{GNs} / \mathrm{Pt}$ & ITO glass & Microwave-assisted synthesis/chemical reduction & $\mathrm{I}^{-} / \mathrm{I}_{3}^{-}$ & N719 & $2.65^{*}$ & 0.68 & 5.10 & [58] \\
\hline
\end{tabular}

${ }^{*}$ Represents that the unit of the $R_{\mathrm{ct}}$ value is $\Omega$.

spectroscopy (EIS) and cyclic voltammetry (CV), the electrocatalytic activity of VG was systemically elucidated. The VG CE not only exhibited lower $R_{\text {ct }}$ value $\left(7.3 \times 10^{-3} \Omega \mathrm{m}^{2}\right)$ than Pt-based CE but also presented higher peak current and smaller peak-to-peak potential separation $\left(\Delta E_{\mathrm{p}}\right)$ compared to the Pt CE. This signifies the excellent electrocatalytic activity of VGCEs for reduction of $\mathrm{I}_{3}{ }^{-}$to $\mathrm{I}^{-}$, therefore resulting in that the DSSC assembled with the VG CE exhibited a relatively higher PCE of 5.36\% than that based on the Pt CE (4.36\%). Impressively, Wang et al. [44] synthesized the novel graphene sheet with 3D honeycomb-like structure based on a simple reaction between $\mathrm{Li}_{2} \mathrm{O}$ and CO. The PCE of the DSSC based on the $3 \mathrm{D}$ graphene with honeycomb-like structure reached $7.8 \%$, presenting its great potential as an efficient Pt-free CE in DSSC. Yang et al. reported an N-doped few-layer graphene as CE material in DSSCs. According to the inert nature of the pristine graphene, it is usually with limited defects or edge planes [45]. Compared to the pristine graphene CE, N-doped graphene $\mathrm{CE}$ can provide more electrocatalytic sites for charge transfer between $\mathrm{CE} /$ electrolyte interfaces and therefore improve the cell conversion performance. Furthermore, they found that $\mathrm{N}$-doped graphene in DSSC demonstrated great long-term stability due to the great adhesion between graphene materials and FTO substrate.

The commonly ruthenium dyes anchored onto the photoelectrode with $\mathrm{I}_{3}{ }^{-} / \mathrm{I}^{-}$system are considered to be with slow recombination kinetics and thus this promotes rapid dye regeneration. Nevertheless, the potential of $\mathrm{I}_{3}{ }^{-} / \mathrm{I}^{-}$redox couple is $0.35 \mathrm{~V}$ (versus the normal hydrogen electrode, NHE) [49]. As for the oxidation potential of the ruthenium dye, it is only ca. $1.1 \mathrm{~V}$ versus NHE [46]. In a DSSC, the low operating potential window limits its opencircuit voltage $\left(V_{\mathrm{oc}}\right)$ (ca. $0.7 \sim 0.8 \mathrm{~V}$ during the dye generation). To enhance the $V_{\text {oc }}$ value of DSSCs, redox mediators with more positive potential have been developed, such as $\mathrm{Co}(\mathrm{bpy}){ }_{3}{ }^{3+} / \mathrm{Co}$ (bpy) ${ }_{3}{ }^{2+}$ (ca. $0.56 \mathrm{~V}$ versus SHE) [47]. Compared to a DSSC with $\mathrm{I}_{3}{ }^{-} / \mathrm{I}^{-}$redox couple, using $\mathrm{Co}(\mathrm{bpy})_{3}{ }^{3+} / \mathrm{Co}(\mathrm{bpy})_{3}{ }^{2+}$ redox couple possesses larger $V_{\mathrm{oc}}$ value up to $0.9 \sim 1 \mathrm{~V}$. Kavan's group developed a functionalized graphene $\mathrm{CE}$ in $\mathrm{Co}(\mathrm{bpy}){ }_{3}{ }^{3+} / \mathrm{Co}(\mathrm{bpy}){ }_{3}{ }^{2+}$ redox mediators. They reported a high-performance DSSC based on a new system including graphene nanoplatelets (GNP) CE and photoanode conjunction with Y123 dye. It should be noted that the GNP-based DSSC in the Co(bpy $)_{3}{ }^{3+} / \mathrm{Co}(\text { bpy })_{3}{ }^{2+}$ redox mediators revealed relatively superior PCE (ca. 9\%) to that of the Pt-based DSSC (ca. 8\%), signifying that the complex is a promising redox mediator for a novel type of iodine-free DSSCs with $V_{\text {oc }}$ exceeding $1 \mathrm{~V}$ [48]. It was also found that the GNP CE exhibited lower $R_{\mathrm{ct}}$ value and larger exchange currents in $\mathrm{Co}(\mathrm{bpy}){ }_{3}{ }^{3+} / \mathrm{Co}(\mathrm{bpy}){ }_{3}{ }^{2+}$ electrolyte system. This suggests that the GNP CE is one of potential cathode materials in the DSSCs with $\mathrm{Co}(\mathrm{bpy}){ }_{3}{ }^{3+} / \mathrm{Co}(\mathrm{bpy}){ }_{3}{ }^{2+}$ electrolyte system. Kavan's group further reported on the improved fabrication protocol toward optically transparent graphene-based layers, yielding wear-resistant films with good adhesion to FTO [50]. They prepared the single-layer graphene oxide (GO) and GO-GNP composite; as a result, the GO-based electrodes showed better mechanical and electrochemical stability. After the aging tests, GO-based electrodes have less losing in electrocatalytic activity. Moreover, the best electrochemical performance and electrocatalytic ability of the CE prepared with $50 \%$ of GO and $50 \%$ of NGP in Co(bpy $)_{3}{ }^{3+} / \mathrm{Co}(\text { bpy })_{3}{ }^{2+}$ electrolyte system. Roy-Mayhew et al. [24] fabricated the versatile functionalized graphene sheet (FGS) and employed it as CE in the DSSCs with iodine-, cobalt-, and sulfur-based redox mediators. As depicted in Figure 3, the FGS-based DSSCs displayed superior photovoltaic performance to that of the Pt-based DSSCs regardless of the electrolyte systems.

\section{Pt/Graphene Composites}

To enhance the electrocatalytic activity of graphene CEs, a variety of $\mathrm{Pt} / \mathrm{graphene}$ composite CEs are designed and synthesized, which are summarized in Table 2 for comparison. For example, Bajpai et al.'s [54] synthesized Pt nanoparticles (NP) were deposited directly on to graphene using pulsed laser deposition (PLD) method. Pt-NPs were deposited uniformly over micrometer-sized graphene sheets. They found that the graphene/Pt composite with $27 \% \mathrm{Pt}$ loading showed higher PCE, short-circuit current density $\left(J_{\mathrm{sc}}\right)$ and $\left(V_{\mathrm{oc}}\right)$ and no loss of the FF as compared to the cells fabricated with standard expansive Pt CE. Wan et al. [55] 


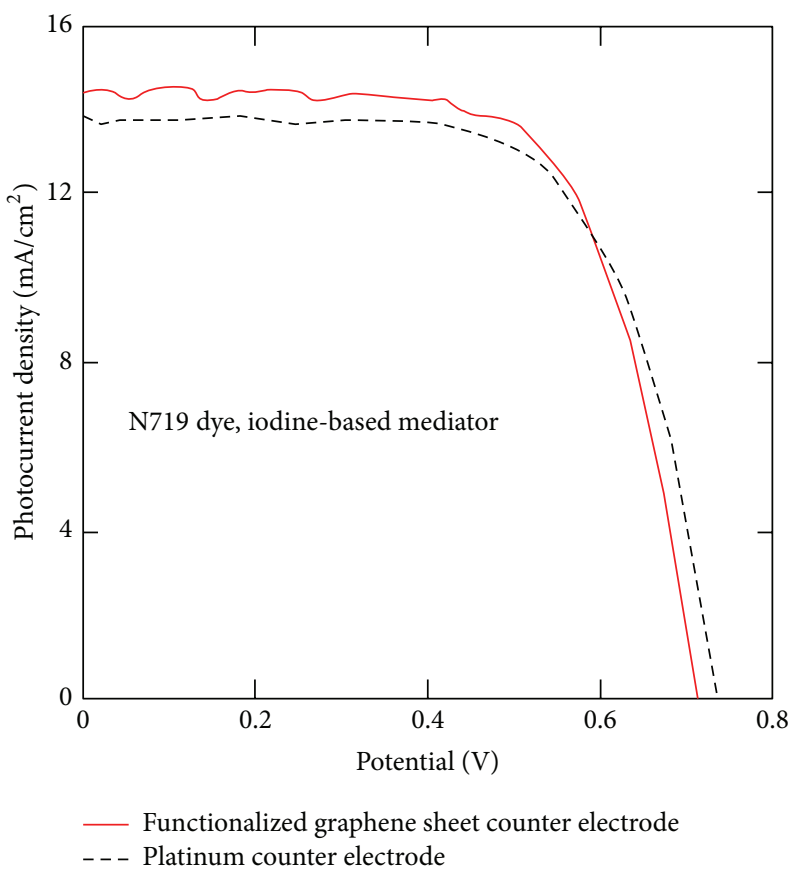

(a)

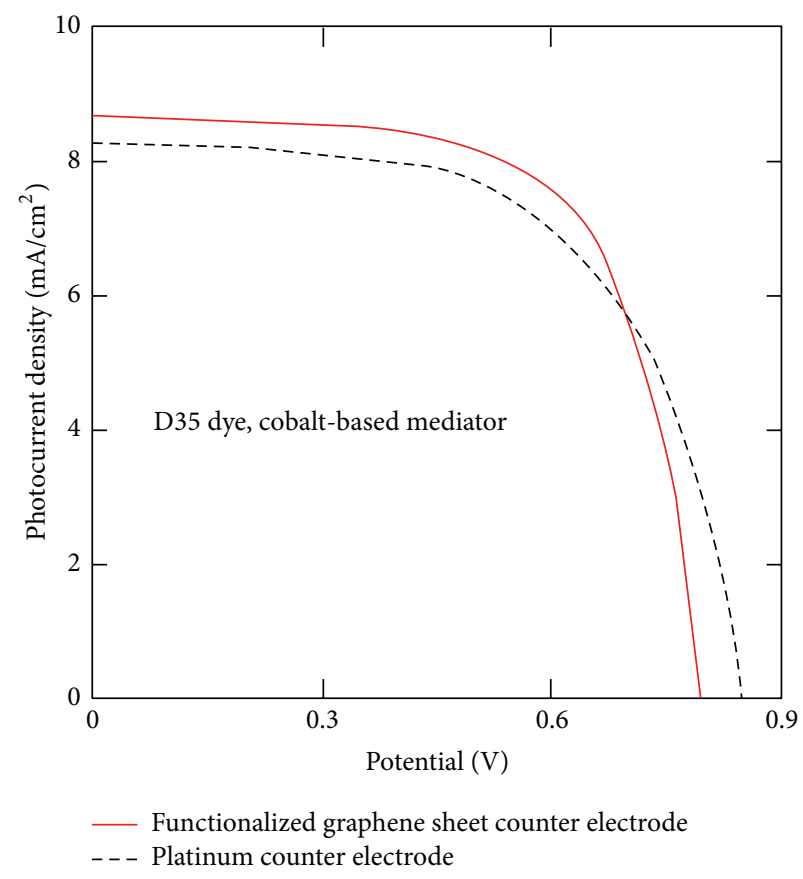

(b)

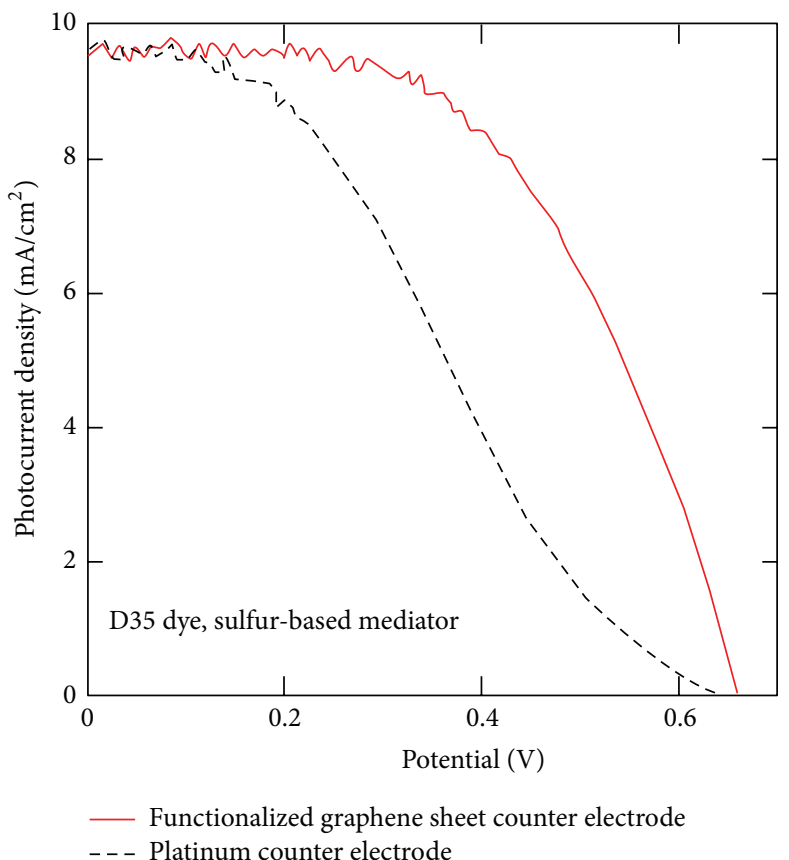

(c)

FIGURE 3: $J-V$ curve characteristics of DSSCs using thermally decomposed chloroplatinic acid (Pt) and FGS counter electrodes. (a) I-based mediator, N719 sensitizer; (b) cobased mediator, D35 sensitizer; (c) S-based mediator, D35 sensitizer. Active area is $0.25 \mathrm{~cm}^{2}$ [24].

synthesized graphene/Pt nanocomposites with low Pt loading via a two-step reduction process. The resultant Pt/graphene composite films were then coated on FTO substrates using a simple drop-casting method at room temperature and subsequently used as CEs in DSSCs. The Pt nanoparticles are ca. 4-20 nm in size and uniformly distributed on the surface of the graphene layers. The energy conversion efficiency of the
$\mathrm{Pt}$ /graphene-based DSSC was found to be $1.9 \%$, close to that of cells with a Pt-based CE. Yen et al. [56] further developed a water-ethylene method to prepare a composite material consisting of $\mathrm{Pt}$ nanoparticles and graphene (PtNP/GR). The PCE value $(6.35 \%)$ of the DSSCs using PtNP/GR CE was higher than Pt CE-based DSSCs (5.27\%), which was attributed to the increase in $J_{\text {sc }}$ value by $13 \%$. Kim's group 
[57] prepared aqueous dispersible nanohybrids (NHBs) of graphene nanosheets (GNSs) and Pt nanoparticles (Pt-NPs) via the one-pot reduction of their precursors by using an environmentally friendly chemical, vitamin C. Moreover, the GNS/Pt-NHBs CE was simply fabricated by a facile electrospray approach from the as-prepared stable aqueous colloidal dispersion of GNS/Pt-NHBs. The main advantage of using electrospray to prepare the GNS/Pt-NHBs CE is that the GNS/Pt-NHBs hybrid materials can be directly deposited on the surface of FTO substrates without using any organic binders. The Pt-NPs were observed to be robustly attached on the surface of the GNSs. The PCE of the DSSC using the GNSs/NHBs CE (7.97\%) was approximately two times higher than that of the DSSC with the GNSs (4.44\%). When the GNS-NHB CEs were with annealing treatment, the PCE of the DSSC assembled with the annealed GNSNHBs CE (8.91\%) was comparable to that of the DSSC based on Pt CE (8.85\%). Dao et al. [58] developed a simple and continuous dry-plasma reduction method to evenly hybrid Pt nanoparticles (Pt-NPs) on reduced graphene oxide (RGO) layer under atmospheric pressure and without using any toxic chemicals. Pt-NPs with a size range of $0.5-4 \mathrm{~nm}$ (mostly $2 \mathrm{~nm}$ ) were found to be dispersed on the surface of RGO. The Pt-NPs/RGO CE displays great electrocatalytic activity as well as excellent long-term stability. The DSSC based on such robust and low-cost CE achieved an impressive PCE of $8.56 \%$. Furthermore, Gong et al. [103] developed a facile electrostatic layer-by-layer self-assembly (ELSA) method to construct ultrathin films composed of graphene nanosheets (GNS) and Pt nanoparticles on the conductive glass as a transparent and high-performance CE. After a series of ELSA treatments, the as-prepared self-assembled film is then sintered and converted to graphene/Pt film on FTO glass substrate. The DSSC with the monolayer GNS/Pt CE achieved a PCE of $7.66 \%$, which was comparable to that using the expensive sputtered Pt CE (8.16\%) Yue et al. [104] employed a facile one-step electrochemical deposition method to prepare Pt nanoparticles/graphene nanosheets (PtNP/GN) films, in which the deposition bath was composed of $\mathrm{H}_{2} \mathrm{PtCl}_{6}$ and GN. After optimizing the amount of GN (ranging from 0$0.25 \mathrm{wt} \%$ ) in the deposition bath, the PtNP/GN-based DSSC achieved a high PCE of $7.88 \%$, which is increased by $21 \%$ compared with a device based on traditional Pt CE. Yeh et al. [25] synthesized graphene/Pt nanoparticles (GN/PtNPs) catalysts with various PtNP loadings (10-60 wt\%) using a polyol reduction method. As depicted in Figure 4, the DSSC with the GN/PtNPs-20\% CE shows the higher PCE of $8.79 \%$ as compared to cells with pristine GN (7.65\%) and s-Pt CEs (8.58\%). Thus, the efficient and economical GN/PtNPs-20\% nanocomposite is a potential candidate for replacing the expensive Pt CE in DSSCs. To reduce the cost and time consumption for production, Saranya et al. [105] tried to employ a microwave-assisted exfoliation method followed by a chemical reduction by chloroplatinic acid for synthesizing graphene nanosheets (GNs)/Pt composites, in which only $160 \mathrm{~s}$ reaction time was required to the intercalation and exfoliation of the graphite to form GNs. The device assembled with the as-prepared Pt-decorated GNs achieved a PCE of

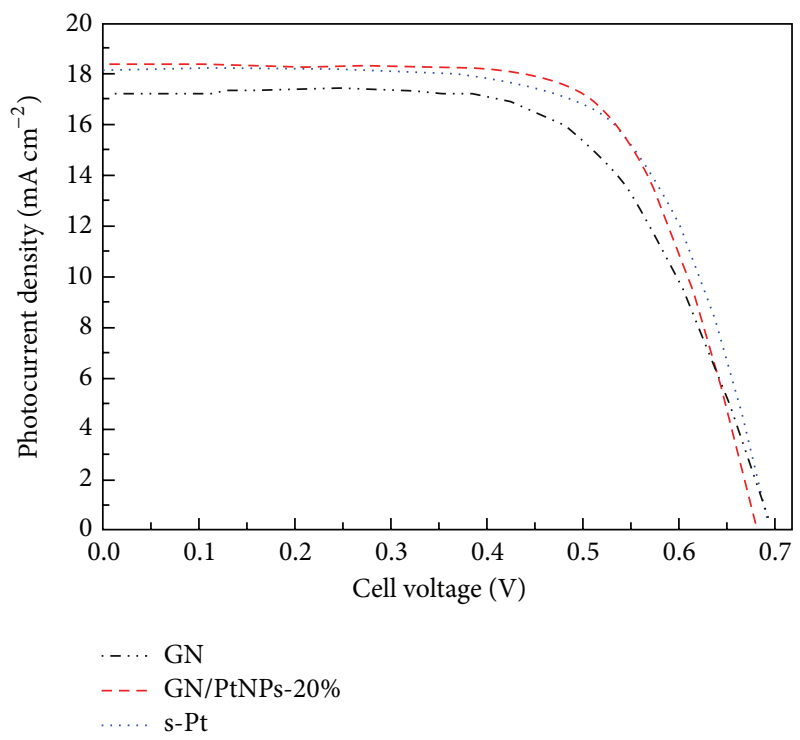

\begin{tabular}{lccccc}
\hline $\mathrm{CE}$ & $\eta(\%)$ & $V_{\mathrm{oc}}(\mathrm{V})$ & $J_{\mathrm{sc}}\left(\mathrm{mA} \mathrm{cm}^{-2}\right)$ & $\mathrm{FF}$ & $R_{\mathrm{ct} 1}(\Omega)$ \\
\hline $\mathrm{GN}$ & $7.65 \pm 0.12$ & $0.70 \pm 0.02$ & $17.08 \pm 0.41$ & $0.64 \pm 0.02$ & 9.12 \\
$\mathrm{GN} /$ PtNPs- & $8.79 \pm 0.21$ & $0.69 \pm 0.01$ & $18.19 \pm 0.58$ & $0.70 \pm 0.01$ & 5.85 \\
$20 \%$ & & & & & \\
$\mathrm{~s}-\mathrm{Pt}$ & $8.58 \pm 0.15$ & $0.69 \pm 0.01$ & $17.77 \pm 0.37$ & $0.70 \pm 0.01$ & 6.45
\end{tabular}

FIGURE 4: Photocurrent density-voltage curves of DSSCs with CEs containing pristine GN, GN/PtNPs-20\%, and s-Pt, obtained at $100 \mathrm{~mW} \mathrm{~cm}^{-2}$ (AM, $1.5 \mathrm{G}$ ) [25].

$5.11 \%$, which is increased by $11 \%$ compared to that reported for other similar systems.

\section{Graphene/Carbon Material Composites}

To achieve high-performance of graphene-based CEs, lots of research has been reported on hybrid graphene with other kinds of carbon materials including carbon nanotubes (CNTs), carbon black, and mesoporous carbon. For instance, the combination of 1-D CNT with 2-D graphene has been proposed to promote the electron transfer and ionic diffusion and therefore facilitate the charge transfer between CE and electrolyte [106], as shown in Table 3. Choi et al. [59] fabricated a CE composed graphene and multiwalled carbon nanotube (MWCNT) by a CVD method. The incorporation of graphene in the MWCNT matrix can provide another area for $\mathrm{I}_{3}{ }^{-}$reduction and thereby the effectively enhanced electrocatalytic activity can be expected for the graphene/MWCNT CE. The cell with the graphene/MWCNT displayed an excellent FF value of 0.7 and exhibited a PCE of $4.46 \%$. Li et al. [60] prepared vertically aligned carbon nanotubes (VACNTs) on a freestanding graphene paper (GP) by CVD. The direct deposition of VACNTs on highly conductive GP can facilitate the ionic diffusion within the composite electrode and electrons transfer at $\mathrm{CE} /$ electrolyte interface. As a result, the VACNT/GP CE displayed higher FF and PCE of 0.64 and $6.05 \%$, respectively, compared with pure GP and VACNT/GP CE. Compared to conventional CVD method of growing graphene film to the desired substrates 
TABLE 3: Photovoltaic performance of the DSSCs based on various graphene/carbon material CEs.

\begin{tabular}{|c|c|c|c|c|c|c|c|c|}
\hline $\mathrm{CE}$ & Substrate & Preparation method & Redox couple & Dye & $R_{\mathrm{ct}}\left(\Omega \mathrm{cm}^{2}\right)$ & $\mathrm{FF}$ & PCE (\%) & Ref \\
\hline GMWNT & FTO glass & CVD & $\mathrm{I}^{-} / \mathrm{I}_{3}^{-}$ & N719 & - & 0.70 & 4.46 & [59] \\
\hline VACNT/GP & GP paper & CVD & $\mathrm{I}^{-} / \mathrm{I}_{3}^{-}$ & N719 & 3.40 & 0.62 & 6.05 & {$[60]$} \\
\hline GPMWNT & FTO glass & CVD & $\mathrm{I}^{-} / \mathrm{I}_{3}^{-}$ & N719 & - & 0.70 & 3.00 & {$[61]$} \\
\hline GG-CNT & FTO glass & Electrophoretic deposition & $\mathrm{I}^{-} / \mathrm{I}_{3}^{-}$ & N719 & 49.00 & 0.61 & 6.17 & {$[26]$} \\
\hline Graphene-SWNT & FTO glass & Electrophoretic deposition & $\mathrm{I}^{-} / \mathrm{I}_{3}^{-}$ & N719 & $16.20^{*}$ & 0.57 & 5.17 & {$[62]$} \\
\hline OMC-GNS & FTO glass & Doctor-blade & $\mathrm{I}^{-} / \mathrm{I}_{3}^{-}$ & N719 & 67.76 & 0.61 & 6.82 & {$[63]$} \\
\hline G@OMC & FTO glass & Doctor-blade & $\mathrm{I}^{-} / \mathrm{I}_{3}^{-}$ & N719 & 3.32 & 0.63 & 6.38 & [64] \\
\hline MWNT/GNS & FTO glass & Doctor-blade & $\mathrm{I}^{-} / \mathrm{I}_{3}^{-}$ & N719 & $1.10^{*}$ & 0.58 & 4.00 & {$[65]$} \\
\hline Graphene-CB & FTO glass & Doctor-blade & $\mathrm{I}^{-} / \mathrm{I}_{3}^{-}$ & N719 & $0.27^{*}$ & 0.57 & 5.99 & {$[66]$} \\
\hline MWNT/Gr-F & FTO glass & Dry spun & $\mathrm{I}^{-} / \mathrm{I}_{3}^{-}$ & N719 & $1.70^{*}$ & 0.63 & 7.55 & [67] \\
\hline $\mathrm{CF} / \mathrm{GNP}$ & FTO glass & Spin-coating & $\mathrm{Co}^{3+} / \mathrm{Co}^{2+}$ & Y123 & 1.12 & 0.74 & 9.11 & {$[68]$} \\
\hline GMC & FTO glass & Screen-printing & $\mathrm{T}_{2} / \mathrm{T}^{-}$ & N719 & 1.26 & 0.69 & 6.55 & [27] \\
\hline GP/MWNT & FTO glass & Spin-coating & $\mathrm{I}^{-} / \mathrm{I}_{3}^{-}$ & N719 & 2.94 & 0.53 & 4.66 & [69] \\
\hline GR/MWCNT & FTO glass & Spray & $\mathrm{I}^{-} / \mathrm{I}_{3}^{-}$ & N719 & $10.89^{*}$ & 0.49 & 7.70 & [70] \\
\hline NGC & FTO glass & Screen-printing & $\mathrm{I}^{-} / \mathrm{I}_{3}^{-}$ & N719 & 1.78 & 0.49 & 6.19 & {$[71]$} \\
\hline
\end{tabular}

${ }^{*}$ Represents that the unit of the $R_{\mathrm{ct}}$ value is $\Omega$.

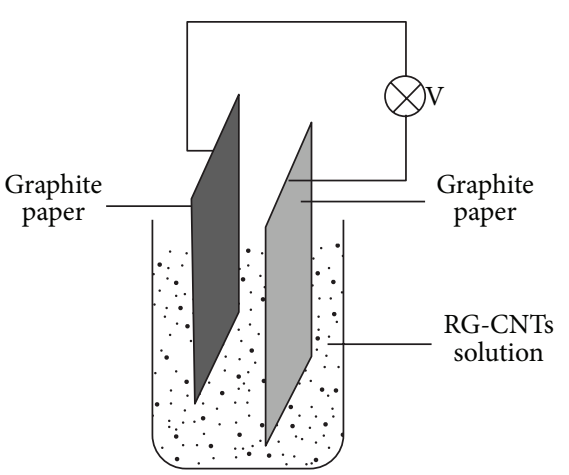

(a)

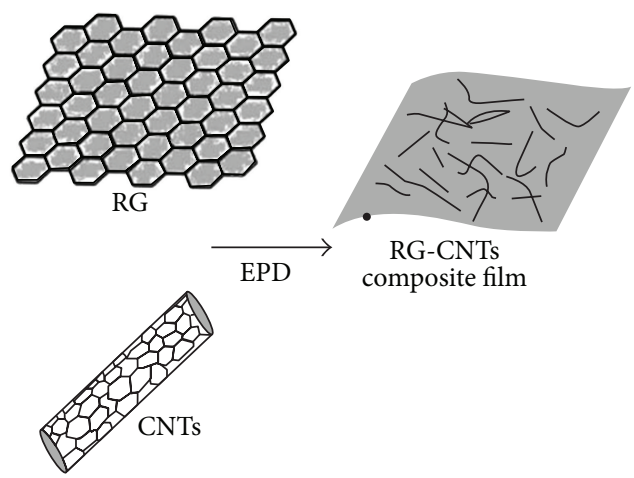

(b)

FIGURE 5: (a) Schematic diagram of EPD process. (b) Structure illustration of RG-CNTs composite films [26].

as CEs, electrophoretic deposition (EPD) is a relatively economical and versatile method to fabricate graphene-based CEs since the thickness of graphene film can be controlled by adjusting the deposition parameters such as deposition time and applied voltage. As depicted in Figure 5, Zhu et al. [26] used a facile EPD approach to prepare reduced graphene (RG)/CNT composite CEs. Among the DSSCs with CNT, RG/CNT and Pt CEs, RG/CNT-based CE exhibited the highest FF value and therefore achieved the impressive PCE. The improved FF value can be ascribed to the short pathway of electron transfer within 2-D graphene sheets and the constructed electrical network by connecting graphene sheets with CNTs. Kim et al. [62] also used EPD method to deposit the graphene, single-walled CNT (SWCNT) and grapheneSWCNT composite on FTO glass substrates. Among them, as-fabricated graphene-SWCNT CE not only exhibited excellent electrocatalytic activity but also displayed the optical transmittance of $67 \%$ at $550 \mathrm{~nm}$. On the other hand, Ma et al. [70] fabricated different transparent 3-D CNT/graphene CEs by controlling the spraying time and supporting with a mirror to reharvest the reflected light. The 30\% transmittance of composite showed the highest conversion efficiency $(7.70 \%)$ with a mirror for $J_{\mathrm{sc}}$ increasing to $0.83 \mathrm{~mA} \mathrm{~cm}^{-2}$.

In addition, Miao et al. [66] revealed highly electrocatalytic composite CEs based on the combination of the rapid electron transport of graphene and high surface area of carbon black. The moderate bundles of graphene homogeneously distributed within carbon black were observed for the composite CE synthesized in the ratio of graphene and carbon black in $1: 3$. This would therefore provide some space for electrolyte diffusion. The improved electron transport and electrolyte of the optimized composite CE would promote the electrons transfer and provide more effective active sites for $\mathrm{I}_{3}{ }^{-}$reduction. The DSSC based on the graphene/carbon black showed a PCE of 5.99\%. On the other hand, ordered mesoporous carbon (OMC) has attracted extensive attention because of its great chemical stability, fast infiltration of electrolyte, effective catalysis area, and large pore volume [107]. However, OMC with random boundaries usually has low electron mobility and thus its electrocatalytic activity is 


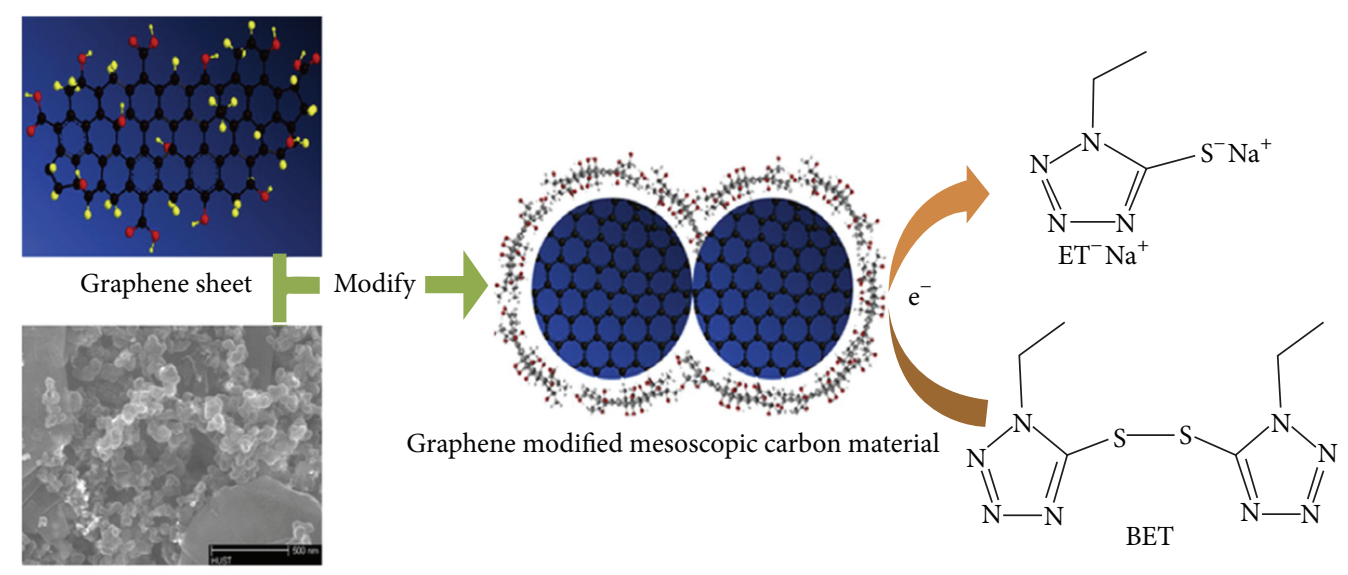

FIGURE 6: Fabrication of graphene modified mesoscopic carbon (GMC) material toward a new synthesized thiolate/disulfide redox couple $\left(\mathrm{ET}^{-} / \mathrm{BET}\right)[27]$.

insufficient as CE material in DSSCs [64]. To address the weakness of OMC, Sun et al. [64] combined OMC with highly conductive reduced graphene oxide (RGO) to form a OMC/RGO composite CE. Therefore, the device with the OMC/RGO composite CE exhibited higher PCE of $6.38 \%$ than that based on the OMC CE (5.67\%). More recently, Shao et al. [63] prepared OMC/graphene nanosheet (GNS) composite with different weight ratios of GNS ranging from 5 to $50 \mathrm{wt} \%$. The optimized OMC/GNS composite CE with $25 \mathrm{wt} \%$ GNS displayed the most excellent electrocatalytic activity and yielded the highest PCE of $6.82 \%$, which rivaled that of the cell with Pt CE (7.08\%). The improved photovoltaic performance of the aforementioned OMC/graphene-based composite CEs is mainly ascribed to the increased pathway for electron transfer by the introduction of highly conductive graphene sheets.

In addition to $\mathrm{I}_{3}{ }^{-} / \mathrm{I}^{-}$redox couple, several graphene/carbon materials were employed as CEs for iodine-free DSSCs. Recently, Liu's group [27] utilized graphene modified mesoscopic carbon (GMC) as CE in DSSCs with thiolate/disulfide $\left(\mathrm{ET}^{-} / \mathrm{BET}\right)$ mediator as illustrated in Figure 6 and obtained significantly improved $\mathrm{FF}$ value, in which the FF value of mesoscopic carbon (NC) and GMC was $32.5 \%$ and $72.5 \%$, respectively. Thus, remarkably enhanced PCE of $6.55 \%$ was achieved for the GMC-based device, which was much higher than that of the NC-based one. The EIS measurements confirmed that the $R_{\mathrm{ct}}$ value of GMC CE was only $1.26 \Omega \mathrm{cm}^{2}$, which was almost ten times lower than that of $\mathrm{NC} \mathrm{CE}$ $\left(12.87 \Omega \mathrm{cm}^{2}\right)$. The low $R_{\mathrm{ct}}$ value of the GMC CE is accounted for its low FF value. As a result, the GMC-based DSSC with disulfide redox couple system exhibited a superior PCE, which was increased by $35 \%$ than that of the GC-based one. As for coupling with $\mathrm{Co}(\mathrm{bpy})_{3}{ }^{3+} / \mathrm{Co}(\mathrm{bpy})_{3}{ }^{2+}$ redox couple, Stefik et al. [68] developed a novel type of cathode composed of carbon fibers (CF) and graphene nanoplatelets (GNP). The CF/GNP composite CE was fabricated by embedding GNP in a conductive carbon matrix derived from the carbonization of poly(acrylonitrile) (PAN). This approach was found to effectively improve the adhesion of GNP with the conductive glass substrates. After the optimization, the CF/GNP CE containing 20\% GNP not only showed the lowest $R_{\mathrm{ct}}$ value of $1.12 \Omega \mathrm{cm}^{2}$ but also displayed its stable mechanical strength against mechanical aging tests. The DSSCs with the optimized CF/GNP CEs have the prominent PCE of 9.11\%, which was higher than that of the cell based on Pt CE (8.61\%).

\section{Graphene/Conducting Polymer Composites}

Organic conducting polymers, such as polyaniline (PANI), poly(3,4-ethylenedioxythiophene) (PEDOT), and polypyrrole (PPy), have also attracted lots of attention to be considered as potential CE materials due to their desirable characteristics of low-cost, environmental stability, high degree of processability, and interesting electrocatalytic properties. As depicted in Table 4, to improve the electrocatalytic of conducting polymers for $\mathrm{I}_{3}{ }^{-}$reduction, highly conductive graphene are generally incorporated into the matrix of conducting polymers to increase their electrical conductivity for rapid electron transfer. For example, Hong et al. [72] fabricated transparent graphene/polystyreneslufonate doped poly(3,4-ethylenedioxythiophene) (PEDOT-PSS) composite films on conductive glass substrates by spin-coating the aqueous mixture of 1-pyrenebutyrate $\left(\mathrm{PB}^{-}\right)$stabilized graphene and PEDOT-PSS. The graphene sheets were observed to be dispersed uniformly in PEDOT-PSS matrix, and the resultant composite film possessed the combined advantages of the excellent electrocatalytic PEDOT-PSS and the high conductive graphene. The PCE of the device was increased from $2.3 \%$ to $4.5 \%$ with increasing the content of graphene incorporated in the composite film from $0 \mathrm{wt} \%$ to $1 \mathrm{wt} \%$. Moreover, Lee et al. [73] used graphene/PEDOT composite film to replace not only the Pt catalyst but also the transparent conducting oxide (TCO) layer in DSSCs. The cell assembled with such Pt- and TCO-free CE achieved a PCE of $6.26 \%$, while the PCEs of DSSCs with Pt/ITO and PEDOT CEs were $6.68 \%$ and $5.62 \%$, respectively. Yue et al. [74] prepared 
TABLE 4: Photovoltaic performance of the DSSC using various graphene/conducting polymer CEs.

\begin{tabular}{|c|c|c|c|c|c|c|c|c|}
\hline $\mathrm{CE}$ & Substrate & Deposition & Redox couple & Dye & $R_{\mathrm{ct}}\left(\Omega \mathrm{cm}^{2}\right)$ & $\mathrm{FF}$ & PCE (\%) & Ref \\
\hline $\begin{array}{l}\text { Graphene- } \\
\text { PEDOT-PSS }\end{array}$ & ITO glass & Spin-coating & $\mathrm{I}^{-} / \mathrm{I}_{3}^{-}$ & N719 & - & 0.48 & 4.50 & {$[72]$} \\
\hline Graphene/PEDOT & TCO glass & Polymerization & $\mathrm{I}^{-} / \mathrm{I}_{3}^{-}$ & N719 & - & - & 6.26 & {$[73]$} \\
\hline GP/PEDOT-PSS & FTO glass & $\begin{array}{l}\text { Electrochemical } \\
\text { polymerization }\end{array}$ & $\mathrm{I}^{-} / \mathrm{I}_{3}^{-}$ & N719 & 2.74 & 0.65 & 7.86 & {$[74]$} \\
\hline PANI/graphene & FTO glass & Electrodeposition & $\mathrm{I}^{-} / \mathrm{I}_{3}^{-}$ & N719 & $11.49^{*}$ & 0.67 & 7.70 & {$[75]$} \\
\hline PANI-RGO & FTO glass & $\begin{array}{l}\text { Layer-by-layer } \\
\text { electrostatic } \\
\text { adsorption } \\
\text { mechanism }\end{array}$ & $\mathrm{I}^{-} / \mathrm{I}_{3}^{-}$ & N719 & 0.71 & 0.64 & 7.84 & {$[76]$} \\
\hline Ppy/RGO & ITO glass & $\begin{array}{l}\text { electrochemical } \\
\text { Oxidative } \\
\text { polymerization }\end{array}$ & $\mathrm{I}^{-} / \mathrm{I}_{3}^{-}$ & N719 & $32.95^{*}$ & 0.60 & 6.45 & {$[77]$} \\
\hline PANI/graphene & FTO glass & Polymerization & $\mathrm{I}^{-} / \mathrm{I}_{3}^{-}$ & $\mathrm{N} 3$ & 1.10 & 0.67 & 6.09 & [35] \\
\hline
\end{tabular}

${ }^{*}$ Represents that the unit of the $R_{\mathrm{ct}}$ value is $\Omega$.

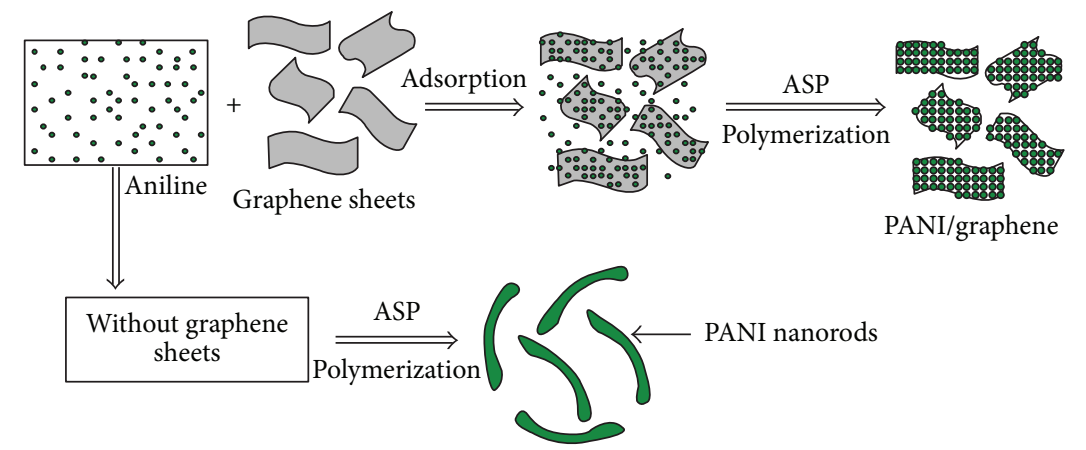

FIgURE 7: Schematic illumination for the synthesis of PANI/graphene hybrid [35].

graphene/PEDOT-PSS composite film on FTO glass substrates using in situ electropolymerization approach, in which the different contents of graphene flakes were included in the deposition bath. The as-deposited graphene/PEDOT-PSS composite film possessed a lot of clusters for providing the active surface area and facilitating the penetration of the liquid electrolyte. The incorporation of $0.05 \mathrm{wt} \%$ graphene within the PEDOT-PSS matrix resulted in the most improvement of the electrocatalytic activity for $\mathrm{I}_{3}{ }^{-}$reduction. The DSSC based on such optimized graphene/PEDOT-PSS CE showed a high $\mathrm{PC}$ of $7.86 \%$, comparable with the performance of the DSSC using the Pt CE (7.31\%). In addition to PEDOT, PANI and PPy conducting polymers have been hybrid with graphene as efficient CEs in DSSCs.

He et al. [75] mixed PANI with graphene as PANI/graphene composites via a refluxing process. It was found that PANI was bonded onto graphene without any interfacial separation; the resulting covalent bonding could improve the electron transfer between PANI and graphene. The DSSC employing the PANI/8 wt\% graphene composite CE provided an impressive PCE of $7.70 \%$ in comparison with $6.40 \%$ from the pristine PANI CE-based device. Wang et al. [76] firstly incorporated GO into PANI matrix via layer-bylayer electrostatic adsorption method. To further enhance the electrical conductivity and electrocatalytic activity of the PANI-GO films, they were reduced with hydroiodic acid in the form of PANI-RGO composite films. They also found that the incorporation of RGO into PANI matrix can increase the transparency of PANI and promote the lightharvesting from the rear side of devices. A cell based on the transparent PANI-RGO CE can achieve an impressive PCE of $7.84 \%$, which is comparable to that assembled with Pt CE (8.19\%). Liu et al. [77] employed a facile two-step electrochemical process to fabricate PPy/RGO composites. Firstly, the PPy/GO composites were obtained by electrochemical oxidative polymerization. Secondly, the GO incorporated in the PPy/GO composites was effectively reduced to RGO through cyclic voltammetry method to obtain PPy/RGO composites. After optimizing the polymerization period of PPy/GO, the DSSC based on the optimized PPy/RGO CE presented a PCE of $6.45 \%$, which was ca. $90 \%$ of that of the device using a thermally deposited Pt CE (7.14\%).

In addition to the mixture of graphene and conducting polymers, Wang et al. [35] synthesized a hybrid material of polyaniline (PANI) nanoparticles dispersed on the graphene prepared using an in situ polymerization method (Figure 7). In their work, the graphene sheets function as highly conductive supports for decorating PANI nanoparticles, thus 
TABLE 5: Photovoltaic performance of the DSSC using various graphene/metal sulfide material CEs.

\begin{tabular}{|c|c|c|c|c|c|c|c|c|}
\hline $\mathrm{CE}$ & Subtract & Deposition & Redox couple & Dye & $R_{\mathrm{ct}}\left(\Omega \mathrm{cm}^{2}\right)$ & $\mathrm{FF}$ & PCE (\%) & Ref \\
\hline $\mathrm{G}-\mathrm{CoS}$ & FTO glass & CVD + SILAR & $\mathrm{I}^{-} / \mathrm{I}_{3}^{-}$ & N719 & 5.05 & 0.36 & 3.42 & [78] \\
\hline CoS/graphene & FTO glass & CVD + Dip-coating & $\mathrm{I}^{-} / \mathrm{I}_{3}^{-}$ & N719 & - & 0.69 & 5.04 & [78] \\
\hline NiS/graphene & FTO glass & CVD + Dip-coating & $\mathrm{I}^{-} / \mathrm{I}_{3}^{-}$ & N719 & 8.60 & 0.70 & 5.25 & [79] \\
\hline $\mathrm{CoS}_{2}-\mathrm{G}$ & FTO glass & Doctor-blade & $\mathrm{I}^{-} / \mathrm{I}_{3}^{-}$ & N719 & 1.30 & 0.60 & 6.55 & [80] \\
\hline NDG/CoS & FTO glass & Spin-coating & $\mathrm{I}^{-} / \mathrm{I}_{3}^{-}$ & N719 & $2.58^{*}$ & 0.74 & 10.71 & [81] \\
\hline CSG & FTO glass & LBL & $\mathrm{I}^{-} / \mathrm{I}_{3}^{-}$ & N719 & $5.70^{*}$ & 0.63 & 5.43 & [82] \\
\hline FGNS & FTO glass & Electrophoretic deposition & $\mathrm{I}^{-} / \mathrm{I}_{3}^{-}$ & N719 & $1.79^{*}$ & 0.64 & 5.54 & [83] \\
\hline $\mathrm{CoS} / \mathrm{RGO}$ & FTO glass & Electrophoretic deposition + IED & $\mathrm{I}^{-} / \mathrm{I}_{3}^{-}$ & N719 & 3.59 & 0.63 & 9.39 & {$[84]$} \\
\hline $\mathrm{NiS}_{2} @ \mathrm{RGO}$ & FTO glass & Drop-casting & $\mathrm{I}^{-} / \mathrm{I}_{3}^{-}$ & N719 & 2.90 & 0.69 & 8.55 & {$[85]$} \\
\hline GP/NiS & FTO glass & Doctor-blade & $\mathrm{I}^{-} / \mathrm{I}_{3}^{-}$ & N719 & $0.63^{*}$ & 0.68 & 7.67 & {$[86]$} \\
\hline NiS-G & FTO glass & Drop-casting & $\mathrm{I}^{-} / \mathrm{I}_{3}^{-}$ & N719 & $8.98^{*}$ & 0.62 & 8.26 & {$[87]$} \\
\hline $\mathrm{MoS}_{2} / \mathrm{RGO}$ & FTO glass & Drop-casting & $\mathrm{I}^{-} / \mathrm{I}_{3}^{-}$ & N719 & 0.57 & 0.66 & 6.04 & {$[36]$} \\
\hline $\mathrm{MoS}_{2}$ /graphene & FTO glass & Doctor-blade & $\mathrm{I}^{-} / \mathrm{I}_{3}^{-}$ & N719 & 2.17 & 0.68 & 5.98 & [88] \\
\hline $\mathrm{MoS}_{2}$-GNS & FTO glass & Electrophoretic deposition & $\mathrm{I}^{-} / \mathrm{I}_{3}^{-}$ & N719 & 2.34 & 0.59 & 5.81 & [89] \\
\hline $\mathrm{MoS}_{2} / \mathrm{FG}$ & FTO glass & Doctor-blade & $\mathrm{I}^{-} / \mathrm{I}_{3}^{-}$ & N719 & 2.67 & 0.61 & 6.07 & [90] \\
\hline $\mathrm{MoS}_{2} / \mathrm{RGO}$ & FTO glass & Electrophoretic deposition & $\mathrm{I}^{-} / \mathrm{I}_{3}^{-}$ & N719 & 5.17 & 0.67 & 7.46 & {$[37]$} \\
\hline $\mathrm{SnS}_{2} @ \mathrm{RGO}$ & FTO glass & Doctor-blade & $\mathrm{I}^{-} / \mathrm{I}_{3}^{-}$ & N719 & $7.24^{*}$ & 0.67 & 7.12 & {$[91]$} \\
\hline SnS/RGO & FTO glass & Drop-casting & $\mathrm{I}^{-} / \mathrm{I}_{3}^{-}$ & N719 & $23.12^{*}$ & 0.49 & 5.30 & {$[92]$} \\
\hline $\mathrm{SnS}_{2} / \mathrm{RGO}$ & FTO glass & Drop-casting & $\mathrm{I}^{-} / \mathrm{I}_{3}^{-}$ & N719 & $5.29^{*}$ & 0.62 & 7.47 & {$[92]$} \\
\hline $\begin{array}{l}\mathrm{Bi}_{2} \mathrm{~S}_{3} \text {-reduced graphene } \\
\text { oxide }\end{array}$ & FTO glass & Doctor-blade & $\mathrm{I}^{-} / \mathrm{I}_{3}^{-}$ & N719 & $9.20^{*}$ & 0.60 & 5.50 & [93] \\
\hline $\mathrm{RGO} / \mathrm{Cu}_{2} \mathrm{~S}$ & FTO glass & Doctor-blade & $\mathrm{I}^{-} / \mathrm{I}_{3}^{-}$ & N719 & $3.24^{*}$ & 0.69 & 7.12 & [94] \\
\hline CIS-G & FTO glass & Doctor-blade & $\mathrm{I}^{-} / \mathrm{I}_{3}^{-}$ & N719 & $2.30^{*}$ & 0.61 & 6.40 & [95] \\
\hline $\mathrm{CuInS}_{2} / \mathrm{RGO}$ & FTO glass & Doctor-blade & $\mathrm{I}^{-} / \mathrm{I}_{3}^{-}$ & N719 & 0.65 & 0.51 & 6.18 & [96] \\
\hline CZTS/graphene & FTO glass & Doctor-blade & $\mathrm{I}^{-} / \mathrm{I}_{3}^{-}$ & N719 & $13.33^{*}$ & 0.66 & 7.81 & [38] \\
\hline
\end{tabular}

* Represents that the unit of the $R_{\mathrm{ct}}$ value is $\Omega$.

providing rapid electron transfer to highly electrocatalytic PANI nanoparticles and increased electrocatalytic active sites for the reduction of $\mathrm{I}_{3}{ }^{-}$. As a result, the DSSC with PANI/graphene counter electrode achieved a PCE of $6.09 \%$, which is comparable to that of the cell with Pt CE (6.88\%).

\section{Graphene/Inorganic Compound Composites}

Except for conventional carbon materials and conducting polymers, great deals of studies have been recently reported for exploring low-cost, highly efficient electrocatalytic materials as CEs in DSSCs. Up to date, inorganic compounds, such as transition metal oxides, nitrides, sulfides, and carbides [1214, 108-110], have demonstrated their promising potential as Pt-free CEs because of their superior electrocatalytic activity. Nevertheless, their electrical conductivity is still insufficient due to numerous defects or grain boundaries in their structures $[16,81,111]$. To address this weakness, the most efficient strategy is to hybridize nanostructured inorganic compounds with highly conductive materials. As mentioned before, graphene is one of the carbon family materials, which can own outstanding electrical conductivity for electron transfer between inorganic compounds nanoparticles and high specific surface area for decorating them. Moreover, the synthesis of nanostructured inorganic compounds on graphene support could provide increased electrocatalytic sites for $\mathrm{I}_{3}{ }^{-}$reduction. The synergic effect of the aforementioned advantages of hybridization of graphene and inorganic compounds nanoparticles would promote the charge transfer between CEs and electrolyte. In this section, the recent developments of the composite CEs composed of graphene and inorganic compounds are summarized in Tables 5 and 6 and compared as follows.

6.1. Graphene/Metal Sulfides. In 2009, Wang et al. [12] first reported an electrochemical deposited cobalt sulfide (CoS) on ITO/PEN film as an efficient CE in DSSCs. Since that, varieties of transition metal sulfides have been investigated as CEs in DSSCs CE. Among them, molybdenum disulfide $\left(\mathrm{MoS}_{2}\right)$, a typically two-dimensional layered stricture, exhibits Mo atoms bonding between the three stacked atomic layers (S-Mo-S) by weak van der Waals interplay. $\mathrm{MoS}_{2}$ has two typical surfaces on the crystals, which are terrace sites on the basal planes and edge sites on the side surfaces. Due to the anisotropic bonding and the general tendency to minimize the surface energy, nanoparticles of layer materials usually exhibit platelet-like morphology, in which the basal planes are exposed. In addition, the $\mathrm{MoS}_{2}$ proposed that the 
TABLE 6: Photovoltaic performance of the DSSCs with various graphene/metal oxide material CEs.

\begin{tabular}{|c|c|c|c|c|c|c|c|c|}
\hline CE & Subtract & Deposition & Redox couple & Dye & $R_{\mathrm{ct}}\left(\Omega \mathrm{cm}^{2}\right)$ & $\mathrm{FF}$ & PCE (\%) & Ref \\
\hline $\mathrm{NiO}-\mathrm{GP}$ & FTO glass & Drop-casting & $\mathrm{I}^{-} / \mathrm{I}_{3}^{-}$ & N3 & 1.72 & 0.61 & 3.06 & [97] \\
\hline $\mathrm{NiO}-\mathrm{NP}-\mathrm{RGO}$ & FTO glass & Dry plasma reduction & $\mathrm{I}^{-} / \mathrm{I}_{3}^{-}$ & N719 & 13.27 & 0.62 & 7.42 & [98] \\
\hline $\mathrm{GNS} / \mathrm{SiO}_{2}$ & FTO glass & Dip-coating & $\mathrm{I}^{-} / \mathrm{I}_{3}^{-}$ & N719 & $39.80^{*}$ & 0.61 & 6.82 & [99] \\
\hline GNs@ZnO & FTO glass & Spin-coating & $\mathrm{I}^{-} / \mathrm{I}_{3}^{-}$ & N719 & 4 & 0.67 & 8.12 & [100] \\
\hline $\mathrm{Mn}_{3} \mathrm{O}_{4} / \mathrm{RGO}$ & FTO glass & Doctor-blade & $\mathrm{I}^{-} / \mathrm{I}_{3}^{-}$ & N3 & $5.24^{*}$ & 0.61 & 5.90 & [101] \\
\hline $\mathrm{La}_{0.65} \mathrm{Sr}_{0.35} \mathrm{MnO}_{3} / \mathrm{RGO}$ & FTO glass & Spin-coating & $\mathrm{I}^{-} / \mathrm{I}_{3}^{-}$ & N719 & $0.71^{*}$ & 0.67 & 6.57 & {$[102]$} \\
\hline $\mathrm{FeO}_{3} / \mathrm{GFs}$ & FTO glass & Screen-printing & $\mathrm{I}^{-} / \mathrm{I}_{3}^{-}$ & N719 & $5.32^{*}$ & 0.68 & 7.45 & {$[39]$} \\
\hline
\end{tabular}

${ }^{*}$ Represents that the unit of the $R_{\mathrm{ct}}$ value is $\Omega$.

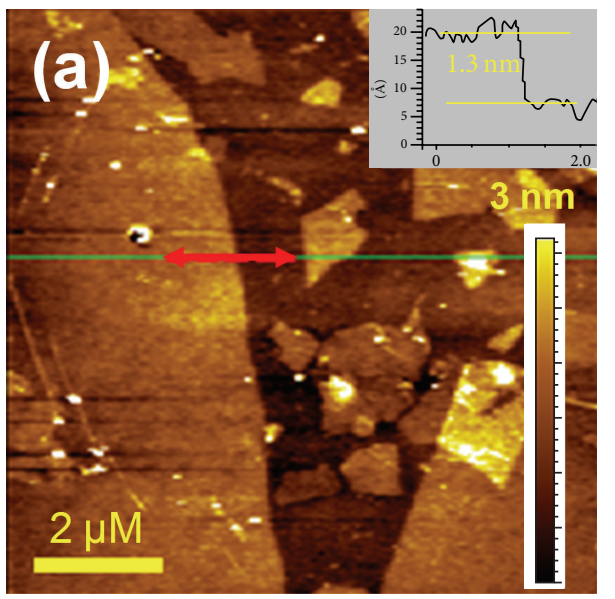

(a)

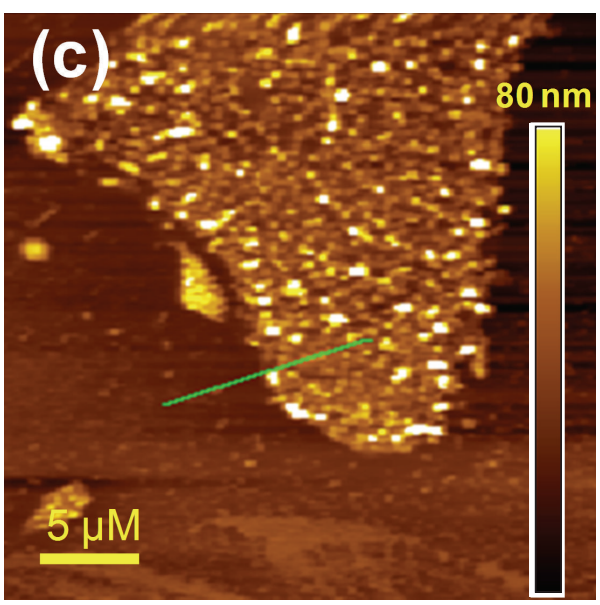

(c)

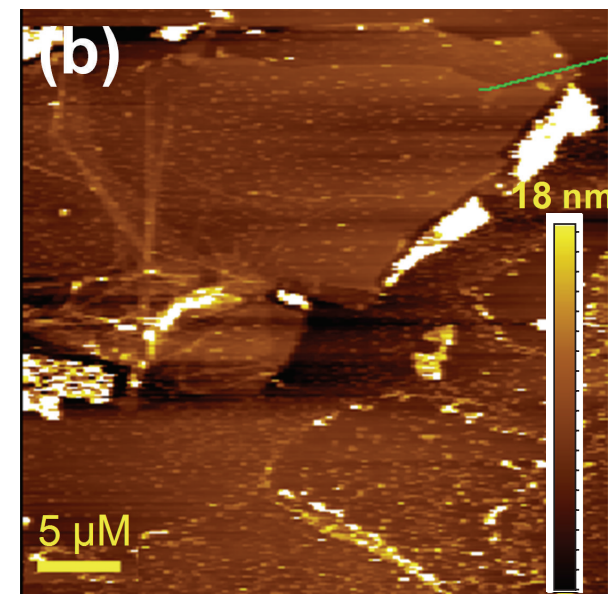

(b)

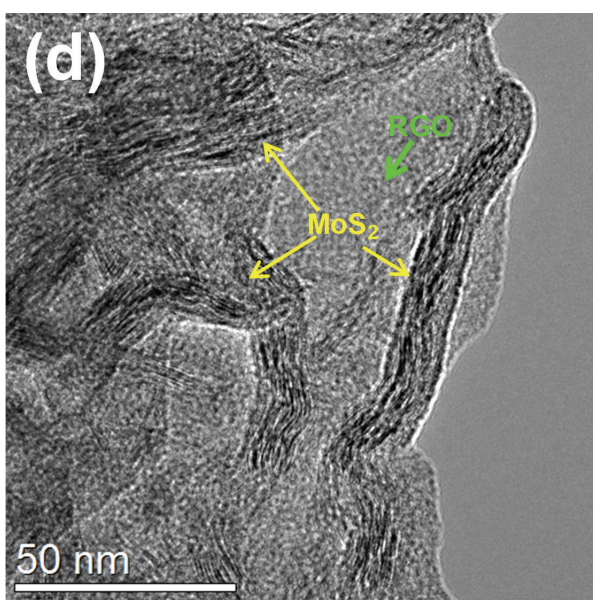

(d)

FIGURE 8: Typical AFM images of (a) as-synthesized GO, (b) RGO with a low loading of $\mathrm{MoS}_{2}$ nanoparticles, and (c) RGO with a high loading of $\mathrm{MoS}_{2}$ nanoparticles. The inset in (a) shows that the height difference between two red arrows is $1.3 \mathrm{~nm}$. (d) TEM image of the MoS $/ \mathrm{RGO}$ nanocomposite [36].

catalytically active sites of $\mathrm{MoS}_{2}$ lie on the edges of the typical layered material but not on the basal planes [112]. To pursue $\mathrm{MoS}_{2}$-based CEs with highly efficient performance in DSSCs, as depicted in Figure 8, our group first decorated $\mathrm{MoS}_{2}$ nanoparticles on reduced graphene oxide (RGO) surface and deposited the composites on FTO glass substrates as efficient CEs using drop-casting method. The extensive cyclic voltammograms (CVs) showed that the cathodic current density of the $\mathrm{MoS}_{2} / \mathrm{RGO} \mathrm{CE}$ was higher than that of $\mathrm{MoS}_{2}$, RGO, and sputtered Pt CEs, due to the increased active surface area of the former [36]. As depicted in Figure 9, the enhanced electrocatalytic activity of the $\mathrm{MoS}_{2} / \mathrm{RGO} \mathrm{CE}$ can be attributed not only to the superior electrical conductivity of RGO but also to the considerable active surface area of the $\mathrm{MoS}_{2}$ nanoparticles dispersed on the RGO surface. The DSSC assembled with the $\mathrm{MoS}_{2} / \mathrm{RGO} \mathrm{CE}$ showed a comparable 


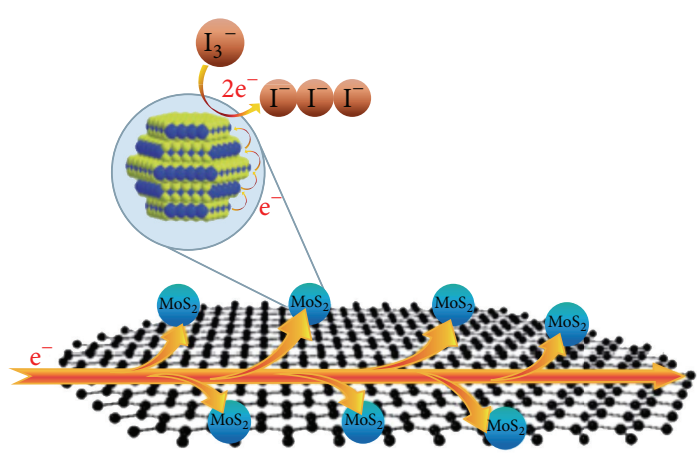

(a)

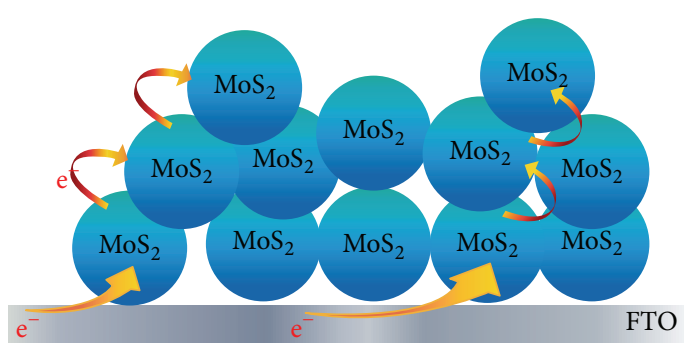

(b)

Figure 9: Schematic of the catalytic mechanisms of (a) $\mathrm{MoS}_{2} / \mathrm{RGO}$ and (b) $\mathrm{MoS}_{2}$ CEs [36].

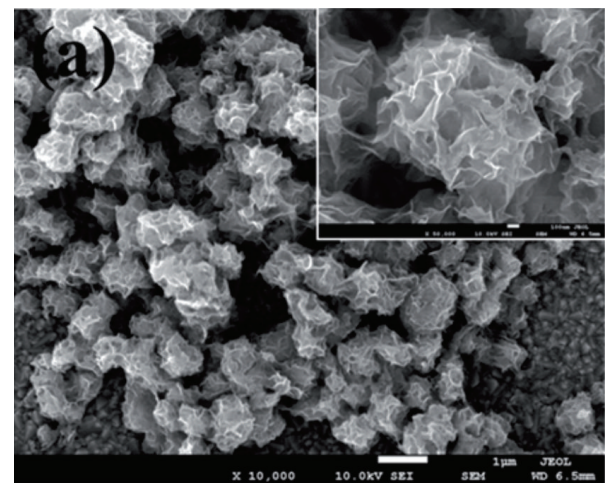

(a)

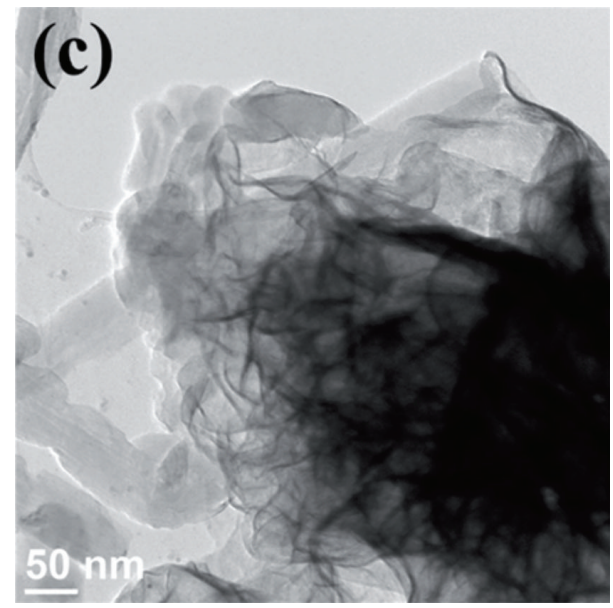

(c)

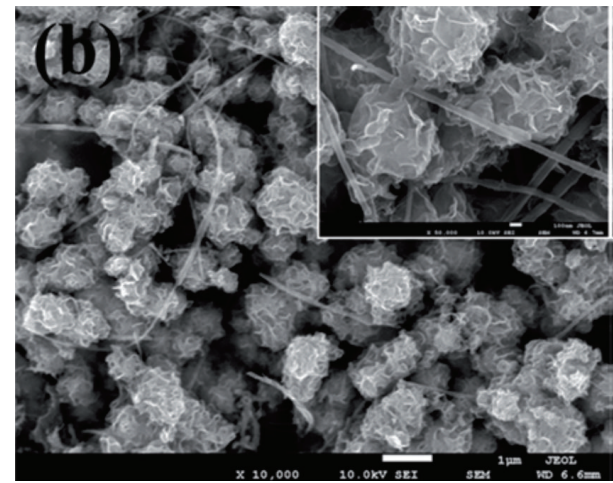

(b)

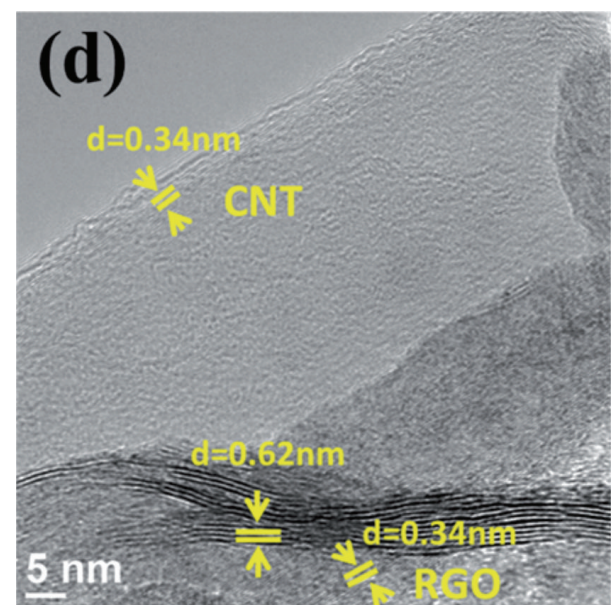

(d)

Figure 10: FESEM images of (a) $\mathrm{MoS}_{2} / \mathrm{RGO}$ and (b) $\mathrm{MoS}_{2} / \mathrm{RGO}-\mathrm{CNTs}$. (c) TEM and (d) HRTEM images of MoS 2 /RGO-CNTs [37].

power conversion efficiency of $6.04 \%$ to the cell with a $\mathrm{Pt}$ CE (6.38\%). Subsequently, our group synthesized transparent $\mathrm{MoS}_{2}$ /graphene nanosheet (GNS) composites via one-pot hydrothermal reaction and deposited them on FTO glass substrates using electrophoretic deposition. The resultant transparent $\mathrm{MoS}_{2} / \mathrm{GNS}$ composite CE demonstrated both high transmittance $(>70 \%)$ at visible wavelengths and improved electrocatalytic activity. The DSSC based on the transparent
CE still achieved an impassive PCE of 5.81\%, which is up to $93 \%$ of that obtained with the conventional Pt CE [89]. The use of electrophoretic deposition has the advantages of high deposition rate, controlled thickness, excellent uniformity, large-scale production, and being without any binders. Recently, a hybrid of $\mathrm{MoS}_{2} / \mathrm{RGO}$ and CNTs (as depicted in Figure 10) has been directly deposited onto FTO glass substrate by similar electrophoretic deposition and employed 
as CE materials in DSSCs by our group [37]. Electrochemical studies indicated that the incorporation of CNTs within the $\mathrm{MoS}_{2} / \mathrm{RGO}$ matrix can facilitate the electron transport efficiently and therefore enhance the charge-transfer rate for $\mathrm{I}_{3}{ }^{-}$reduction. Consequently, the DSSC assembled with the $\mathrm{MoS}_{2} / \mathrm{RGO}-\mathrm{CNTs} \mathrm{CE}$ achieves an impressive PCE of $7.46 \%$, which is higher than that of devices that incorporate $\mathrm{MoS}_{2} / \mathrm{RGO}$ CE (6.82\%) or Pt CE (7.23\%) [37].

Additionally, Das et al. [78] decorated CoS nanoparticles on graphene film (G-CoS) via successive ionic layer adsorption and reaction (SILAR) process; therefore, the increased catalytic area for $\mathrm{I}_{3}{ }^{-}$reduction at $\mathrm{CE} /$ electrolyte and $\mathrm{CoS}$ nanoparticles was obtained. Consequently, remarkably improved FF and PCE values for the G-CoS based DSSC were achieved, compared to that with pristine CoS CE. Bi et al. [79] synthesized two kinds of metal sulfides (CoS and $\mathrm{NiS}$ ) and $\mathrm{CoS}$ /graphene and NiS/graphene composites as Ptfree CEs. Firstly, 3D graphene was directly deposited on $\mathrm{SiO}_{2}$ substrate, serving not only as conductivity layer for electron transfer but also as support for decorating CoS or NiS nanoparticles. In recorded CV curves, the cathodic current densities of CoS/graphene and $\mathrm{NiS} /$ graphene CEs were obviously higher than those of CoS/FTO, NiS/FTO, and Pt/FTO, indicating that the composites CEs have higher electrocatalytic activity for $\mathrm{I}_{3}{ }^{-}$reduction. Moreover, both $\mathrm{NiS} /$ graphene and CoS/graphene CEs showed the smaller $R_{\mathrm{ct}}$ of 8.6 and $8.8 \Omega \mathrm{cm}^{2}$ than that of the NiS/FTO $\left(20.5 \Omega \mathrm{cm}^{2}\right)$, CoS/FTO $\left(26.4 \Omega \mathrm{cm}^{2}\right)$, and Pt/FTO $\left(9.1 \Omega \mathrm{cm}^{2}\right) \mathrm{CEs}$, signifying the significantly improved charge transfer at $\mathrm{CE} /$ electrolyte for the NiS/graphene and CoS/graphene CEs. The improved PCE values of $5.25 \%$ and $5.04 \%$ were found for the DSSCs based on the NiS/graphene and CoS/graphene CEs. This can be ascribed to their improved FF values of 0.72 and 0.69 , respectively. More recently, Duan et al. [80] synthesized the $\mathrm{CoS}_{2}$ /graphene composite by a facile hydrothermal reaction and utilized doctor-blade method to prepare CEs. The incorporation of graphene significantly controlled $\mathrm{CoS}_{2}$ particles size and offered large reaction surface at $\mathrm{CE} /$ electrolyte. Therefore, $\mathrm{CoS}_{2}$ /graphene composite $\mathrm{CE}$ could provide an efficient diffusion channel for electrolyte penetration and enhanced electrocatalytic activity for $\mathrm{I}_{3}{ }^{-}$reduction. While the DSSC assembled with the $\mathrm{CoS}_{2}$ /graphene composite CE, it displayed a PCE up to $6.55 \%$, which exceeded that of the Ptbased device $(6.20 \%)$.

$\mathrm{Li}$ et al. [85] prepared the nanocomposites of $\mathrm{NiS}_{2}$ with reduced graphene oxide $\left(\mathrm{NiS}_{2} @ \mathrm{RGO}\right)$ by a facile hydrothermal reaction. Compared to RGO and $\mathrm{NiS}_{2} \mathrm{CEs}$, the $\mathrm{NiS}_{2} @ \mathrm{RGO}$ exhibited superior electrocatalytic activity. Therefore, the device with $\mathrm{NiS}_{2} @ \mathrm{RGO} \mathrm{CE}$ exhibited a higher PCE of $8.55 \%$ than that with RGO $(3.14 \%)$ or $\mathrm{NiS}_{2}(7.02 \%)$ CE. This can be explained by the fact that the $\mathrm{NiS}_{2} @ \mathrm{RGO}$ CE possessed lower $R_{\mathrm{ct}}$ value of $2.9 \Omega \mathrm{cm}^{2}$ than that of RGO $\left(100.02 \Omega \mathrm{cm}^{2}\right)$ and $\mathrm{NiS}_{2}\left(8.8 \Omega \mathrm{cm}^{2}\right)$ CEs, therefore revealing the faster charge transfer at $\mathrm{CE} /$ electrolyte. Shen et al. [87] used facile and low-temperature hydrothermal method to synthesize the nanocomposites composed of 1-D $\mathrm{NiS}$ and 2-D graphene (designated as NiS-G) with the ratio of graphene/NiS ranging from 0.2 to 0.6 . Among all devices with NiS-G based CEs, the DSSC based on the NiS-G0.4 CE showed the highest $J_{\mathrm{sc}}$ of $17.05 \mathrm{~mA} \mathrm{~cm}^{-2}$ and PCE of $8.26 \%$, which was much higher than that with pristine graphene (1.56\%) or NiS CE (7.41\%). The appropriate proportion of NiS and graphene could be associated with its morphology and the diffusion resistance, confirming that the loading of NiS fine rods can efficiently hinder the agglomeration of adjacent graphene layers and favor the diffusion of the electrolyte species within the NiS-G CE. Yang et al. [91] synthesized the nanocomposite composed of $\mathrm{SnS}_{2}$ nanoparticles and reduced graphene oxide (designated as $\mathrm{SnS}_{2} @ \mathrm{RGO}$ ). The $R_{\mathrm{ct}}$ values for Pt, RGO, $\mathrm{SnS}_{2}$, and $\mathrm{SnS}_{2} @ \mathrm{RGO}$ are 24.21, 34.20, 39.73, and $17.96 \Omega$, respectively. Compared with RGO and $\mathrm{SnS}_{2}$, $\mathrm{SnS}_{2} @ \mathrm{RGO}$ composite had the lower $R_{\mathrm{ct}}$ value, indicating its higher electrocatalytic activity. Moreover, the DSSCs device with $\mathrm{SnS}_{2} @ \mathrm{RGO}$ composite CE had a remarkable PCE of $7.12 \%$, which was significantly higher than $\mathrm{SnS}_{2} \mathrm{CE}(5.58 \%)$ and RGO CE (3.73\%) and even comparable to the value of $6.79 \%$ obtained with a $\mathrm{Pt}$ reference $\mathrm{CE}$. The synergistic effect between RGO and $\mathrm{SnS}_{2}$ showed both high electrical conductivity and excellent electrocatalytic activity. Zhou et al. also synthesized $\mathrm{CuInS}_{2}$ and RGO by a facile method, and the resultant $\mathrm{CuInS}_{2} / \mathrm{RGO}$ composite was directly employed as $\mathrm{CE}$ material exhibit excellent electrocatalytic activity for the triiodide reduction [95]. The graphene-wrapped $\mathrm{CuInS}_{2}$ composites were exploited as counter electrode for DSSCs and therefore achieved a power conversion efficiency of $6.4 \%$, which is comparable to that of Pt CE (6.9\%) [95].

In addition to wrapping transition metal sulfide nanoparticles on graphene surface, the graphene can be incorporated into metal sulfide matrix to serve the conductive network in metal sulfides. Huo et al. [84] developed the sponge-like $\mathrm{CoS} /$ reduced graphene oxide (CoS/RGO) by electrophoretic deposition and ion exchange deposition. The as-prepared pristine $\mathrm{CoS}$ as $\mathrm{CE}$ has a sponge-like morphology with large specific surface area and low charge-transfer resistance at the CE/electrolyte interface. To further enhance the electrocatalytic activity of sponge-like CoS CEs, the various content of RGO was incorporated in the sponge-like CoS. The composite $\mathrm{CE}$ with the optimized composition ratio (CoS/RGO $\mathrm{RG}_{0.2}$, RGO: $0.2 \mathrm{mgL}^{-1}$ ) revealed the smallest $R_{\mathrm{ct}}$ value of $3.59 \Omega \mathrm{cm}^{2}$, as well as the highest PCE of $9.39 \%$, which was increased by $27.93 \%$ compared with that using Pt CE. Furthermore, Bai et al. [38] synthesized flower-like copper zinc tin sulfide (CZTS) and graphene as composite CE (Figure 11). The CZTS/graphene demonstrated excellent electrocatalytic activity because the incorporation of highly conductive graphene of $2 \mathrm{wt} \%$ remarkably reduced its series resistance $\left(R_{\mathrm{s}}\right)$ from $22.84 \Omega$ to $13.33 \Omega$ and then enhanced the electrical conductivity of the composite CE. Liu et al. [96] employed 3D CuInS 2 microspheres as CE materials and the DSSC based on the CE showed a PCE of only $3.31 \%$. To improve the cell efficiency of the DSSC, the CuInS nanomaterial was hybridized with highly conductive RGO and its cell performance was increased to $6.18 \%$.

6.2. Graphene/Metal Oxide Composites. Bajpai et al. [97] synthesized $\mathrm{NiO}$ nanoparticles homogeneously deposited over few-layered graphene platelets (GPs) by pulsed laser ablation. The device with NiO-GP CE yielded a PCE of 


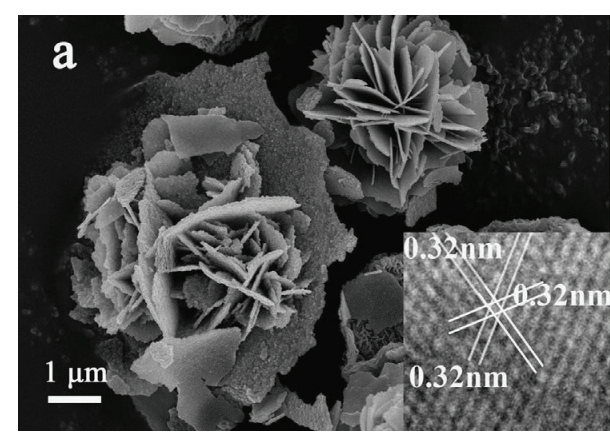

(a)

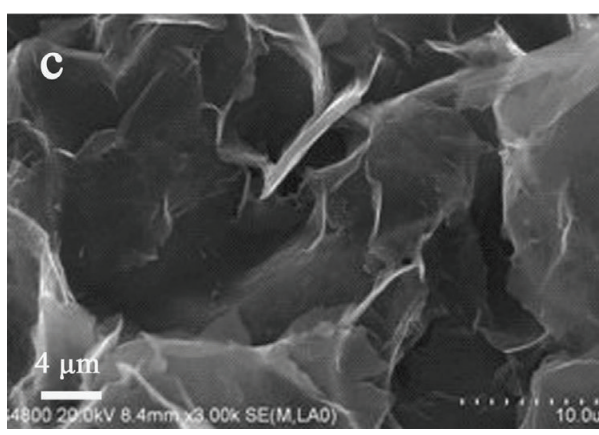

(c)

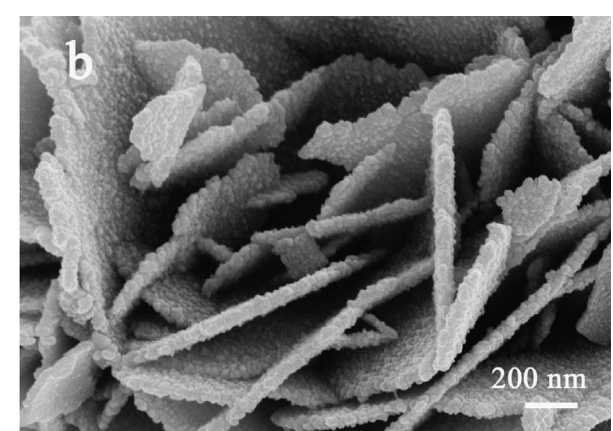

(b)

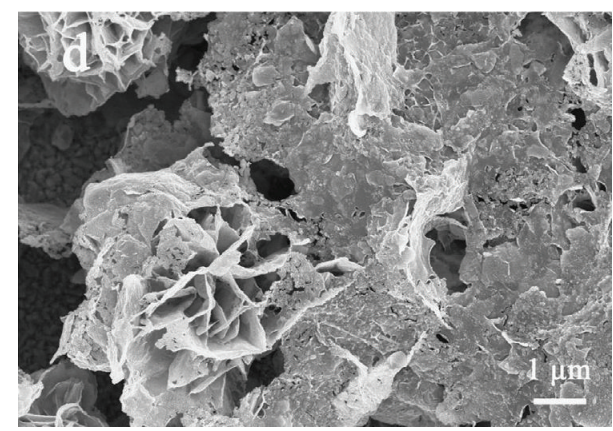

(d)

FIGURE 11: (a) and (b) SEM images of CZTS microspheres. The inset in (a) is HRTEM image of CZTS nanoparticle, (c) SEM image of graphene, and (d) SEM image of annealed CZTS/graphene composites films [38].

$3.06 \%$, which outperformed the cells using unsupported $\mathrm{NiO}$ nanoparticles $(2.03 \%)$ or pristine GPs $(2.46 \%)$ and was even comparable to a conventional Pt-based DSSC (3.57\%). Furthermore, Dao et al. [98] employed dry-plasma reduction to hybridize the $\mathrm{NiO}$ nanoparticles (NiO-NPs) on the surface of RGO. The resultant NiO-NP-RGO CE displayed $R_{\mathrm{ct}}$ value of $1.93 \Omega \mathrm{cm}^{2}$, much lower than that of NiO-NP-immobilized CE $\left(44.39 \Omega \mathrm{cm}^{2}\right)$ and a GO-coated CE $\left(12.19 \Omega \mathrm{cm}^{2}\right)$. In addition, the shunt resistant $\left(R_{\mathrm{h}}\right)$ value of the NiO-NP-RGO $\mathrm{CE}$ measured at a high frequency range was found to be $2.44 \Omega \mathrm{cm}^{2}$, which was slightly lower than the values found for RGO CE $\left(2.45 \Omega \mathrm{cm}^{2}\right)$ and NiO-NP CE $\left(2.53 \Omega \mathrm{cm}^{2}\right)$. This phenomenon can be associated with the decoration of NiO-NPs on the RGO surface, which constructs lots of bridges for facilitating electron transfer between $\mathrm{NiO}-\mathrm{CPs}$ and RGO. Gong et al. [99] synthesized a porous graphene (GNS)/ $/ \mathrm{SiO}_{2}$ nanocomposite converted from graphene oxide mixed with $\mathrm{SiO}_{2}$ nanoparticles through facile hydrazine hydrate reduction. To substantiate the formation of pores within the composite film, the $\mathrm{GNS} / \mathrm{SiO}_{2}$ nanocomposite exhibited a narrow pore size distribution centered at $4.0 \mathrm{~nm}$; thus, $\mathrm{SiO}_{2}$ nanoparticles played a significant role in the GNS layers to build up porous nanostructured architecture. Compared to $\mathrm{SiO}_{2}$ and GNS CEs, the GNS/SiO 2 composite CE demonstrated the lower $R_{\mathrm{s}}$ and $R_{\mathrm{ct}}$ values, displaying its fast electron and charge transfer. Additionally, the porous structure of the $\mathrm{GNS} / \mathrm{SiO}_{2}$ composite film could provide larger surface area than the GNS film, thus enhancing the accessibility of the electrolyte to the inside of $\mathrm{CE}$ and being favorable for the reduction of $\mathrm{I}_{3}^{-}$to $\mathrm{I}^{-}$. As a consequence, DSSC assembled with $\mathrm{GNS} / \mathrm{SiO}_{2} \mathrm{CE}$ achieved high cell efficiency of $6.82 \%$, considered as a promising potential candidate to replace conventional Pt CE. Recently, Chang et al. [100] demonstrated that the combination of graphene nanosheets (GNS) and $\mathrm{ZnO}$ nanorods can be a highly efficient 3-D CE in DSSCs. The use of the $\mathrm{ZnO}$ nanorods as a 3D framework nanostructure could prevent the aggregations of GNs. Unlike conventional chemical functionalization of graphene, the electrocatalytic active sites are created by damaging the conjugated structure in the graphitic basal plan with a concomitant decrease in the electrical conductivity. This novel hybrid system has proved that the GNs were efficiently isolated from each other to prevent the aggregation and restacking of GNs, which increased the active defective sites for the redox reaction of $\mathrm{I}^{-} / \mathrm{I}_{3}{ }^{-}$to improve the electrocatalytic performance. Therefore, the novel hybrid nanoarchitecture exhibited improved performance as a promising candidate CE for DSSCs due to the fast electron transport network and more active sites for catalyzing the $\mathrm{I}_{3}{ }^{-}$reduction. The PCE of the DSSC based on the GNs@ZnO nanorods CE was reached $8.12 \%$, which was comparable to the device using Pt CE $(8.82 \%)$. Interestingly, the inorganic transition metal oxides, $\mathrm{Fe}_{2} \mathrm{O}_{3}$, exhibited approximately identical adsorption energy of iodine compared to that of $\mathrm{Pt}$ in earlier research $[113,114]$. Nevertheless, the cells with $\mathrm{Fe}_{2} \mathrm{O}_{3}$ still obtained low overall conversion efficiency due to the poor electron transport efficiency across $\mathrm{Fe}_{2} \mathrm{O}_{3}$ particles. Yang et al. [39] explored $\mathrm{Fe}_{2} \mathrm{O}_{3}$ nanoparticles (NPs) anchored onto 3D graphene 


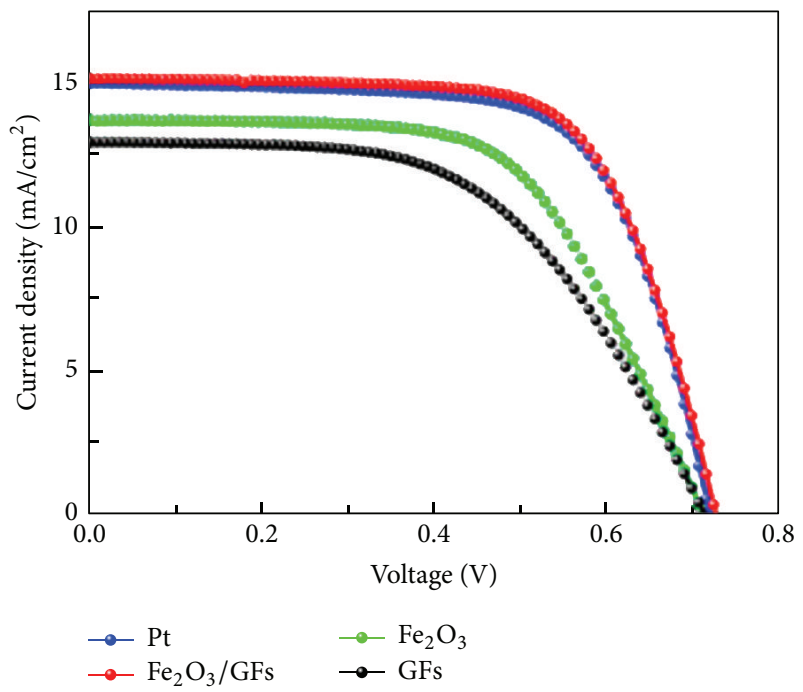

(a)

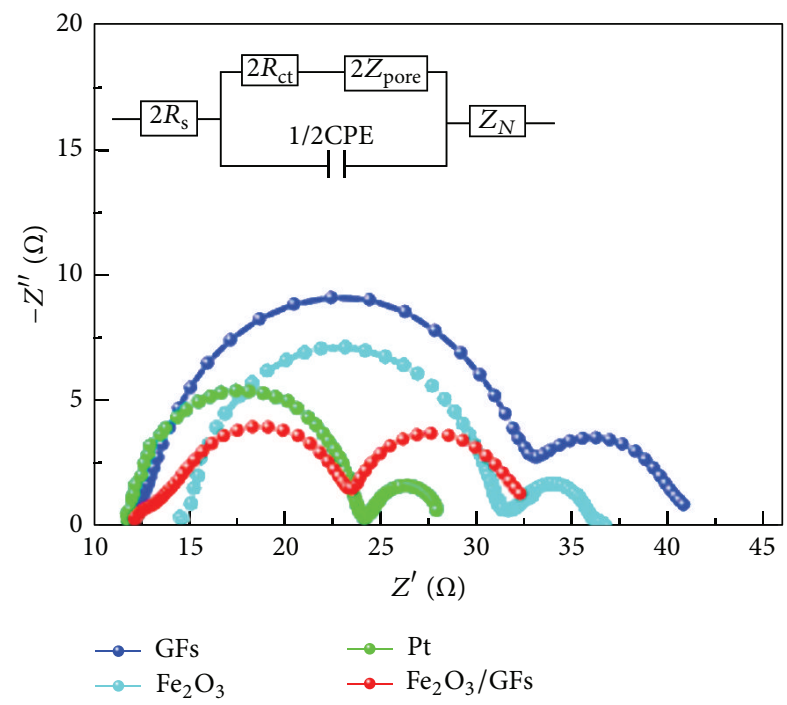

(c)

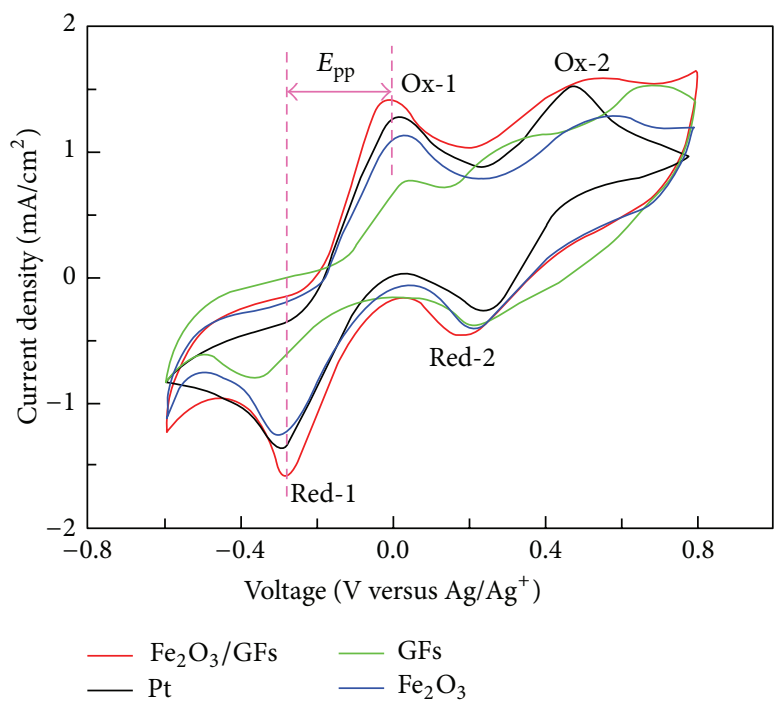

(b)

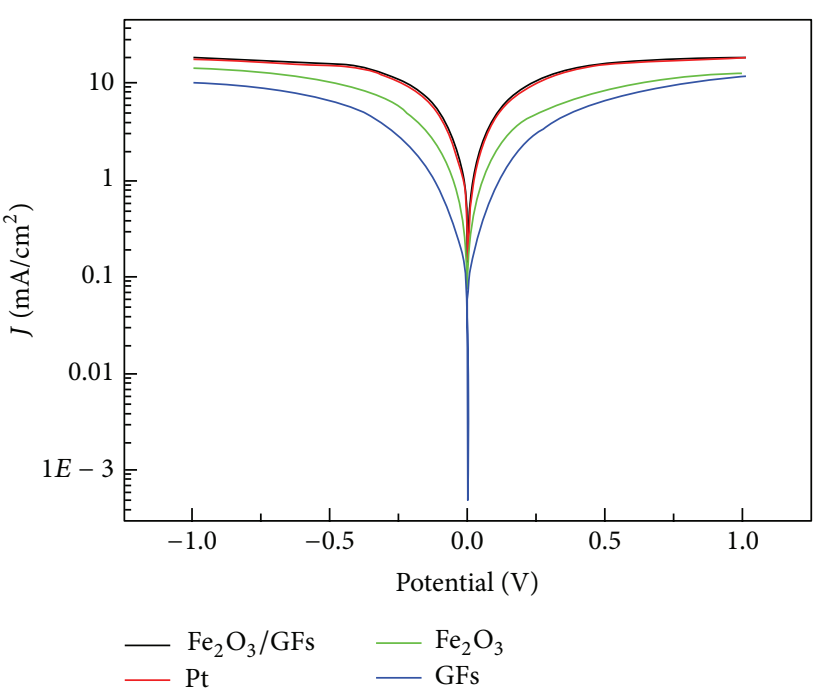

(d)

Figure 12: (a) Current-voltage characteristics of the DSSCs with different CEs under one sun illumination (AM 1.5 G). (b) Cyclic voltammograms of various CEs for $\mathrm{I}^{-} / \mathrm{I}_{3}{ }^{-}$redox species recorded at a scan rate of $50 \mathrm{mV} \mathrm{s}^{-1}$. Electrochemical impedance spectra (c) and (d) Tafel polarization curves of the symmetric dummy cells fabricated with different CEs. (A colored version of this figure can be viewed online [39].)

frameworks (GFs), where $\mathrm{Fe}_{2} \mathrm{O}_{3}$ NPs act as highly active sites for reduction $\mathrm{I}_{3}{ }^{-}$and the $3 \mathrm{D}$ graphene frameworks form an interconnected electron transfer highway system. As can be seen in Figure 12, The DSSCs fabricated with the $\mathrm{Fe}_{2} \mathrm{O}_{3} / \mathrm{GFs}$ CEs showed a higher PCE of 7.45\% in comparison to $7.29 \%$ for the DSSCs with Pt CEs [39]. By EIS, CV and Tafel polarization measurements (also summarized in Figure 12), 3D Fe $\mathrm{O}_{3} / \mathrm{GFs}$ not only obtained high efficiency but also provided multidimensional pathways to facilitate the transport of electrons in the bulk electrode [39]. Due to the fast electron transfer in the interpenetrating graphene frameworks, the shuttle electrons easily cross the graphene sheets to the catalytic $\mathrm{Fe}_{2} \mathrm{O}_{3}$ NPs sites where the electrons are used to reduce $\mathrm{I}_{3}^{-}$. Consequently, $\mathrm{Fe}_{2} \mathrm{O}_{3}$ NPs have lower
$R_{\mathrm{s}}$ and $R_{\mathrm{ct}}$ to reduce the interface loss of charge transfer and enhance charge collection efficiency, thereby boosting the photovoltaic performance of DSSCs.

6.3. Other Inorganic Compound/Graphene Composites. Combination $\mathrm{Ni}_{12} \mathrm{P}_{5}$ and graphene (graphene- $\mathrm{Ni}_{12} \mathrm{P}_{5}$ ) as a unique composite $\mathrm{CE}$ also displayed interesting characteristics of improved electrocatalytic activity, electrical conductivity, and electrolyte penetration [40]. After evaluating the intrinsic electrochemical features of the $\mathrm{Ni}_{12} \mathrm{P}_{5}$, graphene and graphene- $\mathrm{Ni}_{12} \mathrm{P}_{5}$ as CEs in DSSCs, the graphene- $\mathrm{Ni}_{12} \mathrm{P}_{5}$ composite shows optimized electrochemical features, including lower charge-transfer resistance and diffusion impedance by the combination of both contributions of the high 


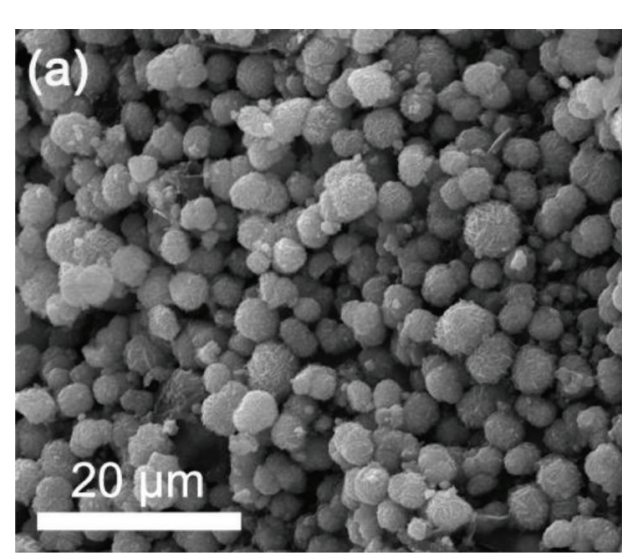

(a)

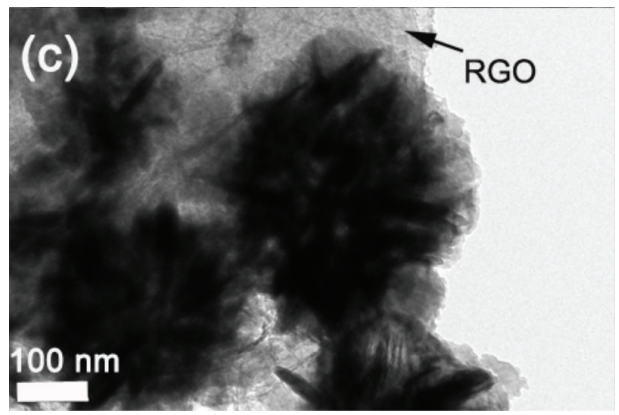

(c)

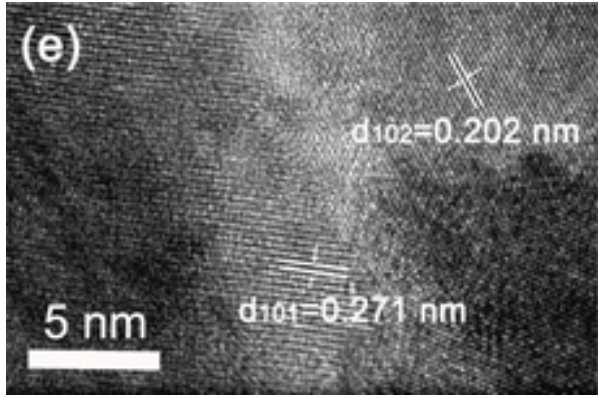

(e)

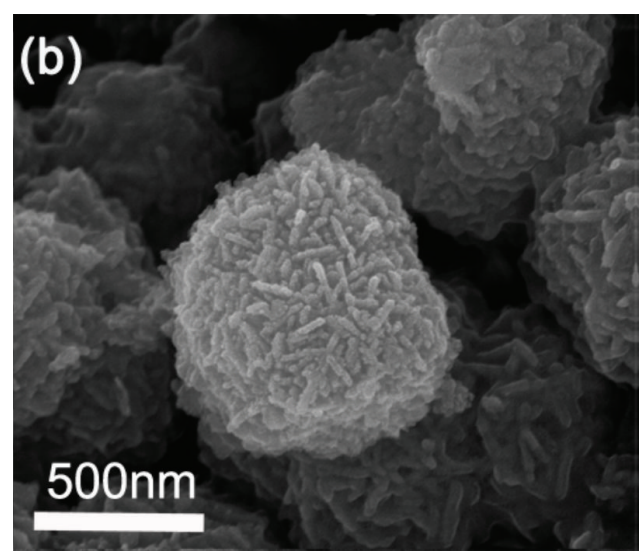

(b)

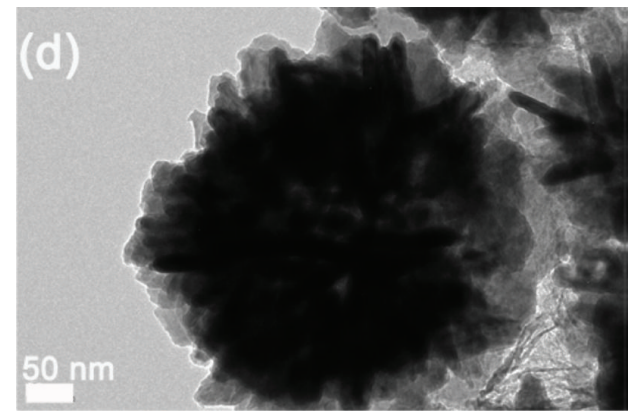

(d)

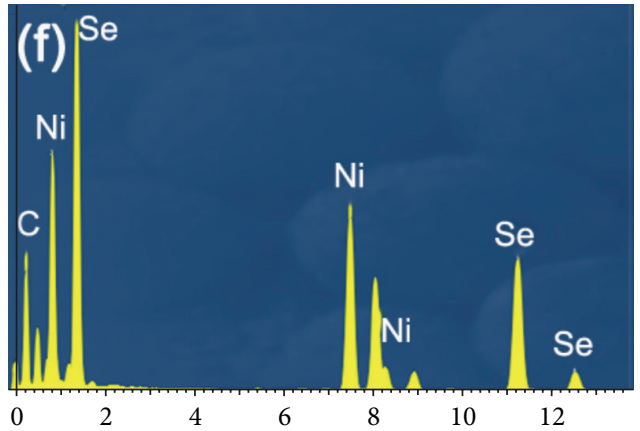

(f)

Figure 13: Typical SEM ((a) and (b)), TEM ((c) and (d)), HRTEM (e), and EDS (f) images of mesoporous Ni ${ }_{0.85} S$ @ RGO nanospheres [40].

electrocatalytic activity of $\mathrm{Ni}_{12} \mathrm{P}_{5}$ nanocrystallites and fast diffusion process of the electrolyte species in the graphene. The main key could relative that the graphene- $\mathrm{Ni}_{12} \mathrm{P}_{5}$ composite as $\mathrm{CE}$ had more active sites and spacers among the graphene layers to accelerate the diffusion of electrolyte species.

On the other hand, some studies have demonstrated that $\mathrm{Ni}_{0.85}$ Se presented excellent electrocatalytic performance for the $\mathrm{I}_{3}{ }^{-}$reduction and can be a potential material as CEs [115]. As can be seen in Figure 13, mesoporous $\mathrm{Ni}_{0.85} \mathrm{Se}$ nanospheres on reduced graphene oxide $\left(\mathrm{Ni}_{0.85} \mathrm{Se} @ \mathrm{RGO}\right)$ were further prepared because the mesoporous structure of $\mathrm{Ni}_{0.85} \mathrm{Se}$ nanospheres and $\mathrm{RGO}$ both possessed large specific surface area and fast electron transfer channels. Consequently, the $\mathrm{Ni}_{0.85}$ Se@RGO CE could provide increased catalytic active sites to reduce $\mathrm{I}_{3}{ }^{-}$and relatively fast electron transfer channels, thus significantly enhancing the electrocatalytic activity of $\mathrm{Ni}_{0.85}$ Se@RGO CE. The PCE of the device with the $\mathrm{Ni}_{0.85}$ Se@RGO CE reached 7.82\%, which was slightly higher than that of Pt CE (7.54\%).

In order to achieve the high-performance of DSSCs with CEs composed of inorganic compounds and carbon materials, graphene sheets doped with heteroatoms such as nitrogen $(\mathrm{N})$, boron $(\mathrm{B})$, and phosphorous $(\mathrm{P})$ can improve their electrocatalytic active sites [116]. Therefore, Balamurugan et al. [117] hybridized iron nitride (FeN) core-shell nanoparticles grown on nitrogen-doped graphene (NG) as CE material for application in DSSCs. In particular, the superior performance of DSSCs with newly developed core-shell FeN/NG nanohybrids was attributed to the high electrical 
conductivity, large surface area, good surface hydrophilicity, enhanced electrolyte/CE interaction, and excellent electrocatalytic activity toward the reduction of iodine redox species. The PCE of the DSSC with core-shell FeN/NG CE reached $10.86 \%$, which was also superior to that of a cell with a conventional Pt CE (9.93\%) under the same experimental conditions.

\section{Summary}

DSSCs have been widely regarded as promising photovoltaic devices to convert incident light to electricity. In accordance with the working mechanism of DSSCs, CEs have to possess both high electrical conductivity and excellent electrocatalytic activity for collecting electron back from external circuit, constructing rapid electron transfer network, and catalyzing $\mathrm{I}_{3}{ }^{-}$reduction reaction. Moreover, low-cost alternative CEs should be explored to replace high-cost noble Pt CE for large-scale applications. As a result, we review a great deal of graphene-based CE materials for low-cost Pt-free DSSCs since graphene has the following specific properties of high electrical conductivity, great anticorrosion resistance, and large surface area. In this study, the electrochemical properties of various graphene-based CEs and their effects on cell performance were systemically discussed. It is found that the pristine graphene does not display sufficient electrocatalytic activity due to its limited electroactive sites. To improve this issue, three approaches have been conducted: (i) the decoration of excellent electrocatalytic nanomaterials on the surface of highly conductive graphene, (ii) the incorporation of graphene in the matrix of electrocatalytic materials to improve its electrical conductivity, and (iii) the introduction of highly conductive materials to connect graphene layers for promoting electron transfer between them. Although lots of studies have been carried out to improve the various aspects of graphene-based CEs in DSSCs, the device performance of most DSSCs is still relatively lower compared with that using a conventional Pt CE.

On the basis of strategies (i) and (iii), although the graphene decorated with highly electrocatalytic nanoparticles has high electrocatalytic activity, it still requires some conductive materials to connect graphene layers for promoting electron transfer. Therefore, the fabrication of the novel hybrids composed of conductive materials/graphene decorated with highly electrocatalytic nanoparticles would be a promising approach to design highly efficient $\mathrm{Pt}$-free alternatives for low-cost DSSCs in the near future.

\section{Competing Interests}

The authors declare that they have no competing interests.

\section{Acknowledgments}

This research was supported by Ministry of Science and Technology, Taiwan (NSC 101-2221-M-036-035 and MOST 103-2221-E-036-014-MY3).

\section{References}

[1] B. O’Regan and M. Grätzel, "A low-cost, high-efficiency solar cell based on dye-sensitized colloidal $\mathrm{TiO}_{2}$ films," Nature, vol. 353, no. 6346, pp. 737-740, 1991.

[2] N. Sridhar and D. Freeman, "A study of dye sensitized solar cells under indoor and low level outdoor lighting: comparison to organic and inorganic thin film solar cells and methods to address maximum power point tracking," in Proceedings of the 26th European Photovoltaic Solar Energy Conference and Exhibition, Hamburg, Germany, September 2011.

[3] G. Calogero, A. Bartolotta, G. Di Marco, A. Di Carlo, and F. Bonaccorso, "Vegetable-based dye-sensitized solar cells," Chemical Society Reviews, vol. 44, no. 10, pp. 3244-3294, 2015.

[4] G. Syrrokostas, A. Siokou, G. Leftheriotis, and P. Yianoulis, "Degradation mechanisms of Pt counter electrodes for dye sensitized solar cells," Solar Energy Materials and Solar Cells, vol. 103, pp. 119-127, 2012.

[5] G. Boschloo and A. Hagfeldt, "Characteristics of the iodide/triiodide redox mediator in dye-sensitized solar cells," Accounts of Chemical Research, vol. 42, no. 11, pp. 1819-1826, 2009.

[6] M. Wu and T. Ma, "Platinum-free catalysts as counter electrodes in dye-sensitized solar cells," ChemSusChem, vol. 5, no. 8, pp. 1343-1357, 2012.

[7] L. Yang, L. Wu, M. Wu, G. Xin, H. Lin, and T. Ma, "Highefficiency flexible dye-sensitized solar cells fabricated by a novel friction-transfer technique," Electrochemistry Communications, vol. 12, no. 7, pp. 1000-1003, 2010.

[8] A. Kanciurzewska, E. Dobruchowska, A. Baranzahi, E. Carlegrim, M. Fahlman, and M. A. Gîrţu, "Study on poly(3,4ethylene dioxythiophene)-poly(styrenesulfonate) as a plastic counter electrode in dye sensitized solar cells," Journal of Optoelectronics and Advanced Materials, vol. 9, no. 4, pp. 10521059, 2007.

[9] Y. Saito, W. Kubo, T. Kitamura, Y. Wada, and S. Yanagida, "I-/I3redox reaction behavior on poly (3,4-ethylenedioxythiophene) counter electrode in dye-sensitized solar cells," Journal of Photochemistry and Photobiology A: Chemistry, vol. 164, no. 1-3, pp. 153-157, 2004.

[10] J. Xia, N. Masaki, K. Jiang, and S. Yanagida, "The influence of doping ions on poly(3,4-ethylenedioxythiophene) as a counter electrode of a dye-sensitized solar cell," Journal of Materials Chemistry, vol. 17, no. 27, pp. 2845-2850, 2007.

[11] Y. Chen, K. S. Kang, K. J. Han, K. H. Yoo, and J. Kim, “Enhanced optical and electrical properties of PEDOT: PSS films by the addition of MWCNT-sorbitol," Synthetic Metals, vol. 159, no. 1718, pp. 1701-1704, 2009.

[12] M. Wang, A. M. Anghel, B. Marsan et al., "CoS supersedes Pt as efficient electrocatalyst for triiodide reduction in dye-sensitized solar cells," Journal of the American Chemical Society, vol. 131, no. 44, pp. 15976-15977, 2009.

[13] Q. W. Jiang, G. R. Li, and X. P. Gao, "Highly ordered TiN nanotube arrays as counter electrodes for dye-sensitized solar cells," Chemical Communications, no. 44, pp. 6720-6722, 2009.

[14] M. Wu, Q. Zhang, J. Xiao et al., “Two flexible counter electrodes based on molybdenum and tungsten nitrides for dye-sensitized solar cells," Journal of Materials Chemistry, vol. 21, no. 29, pp. 10761-10766, 2011. 
[15] G. R. Li, J. Song, G. L. Pan, and X. P. Gao, "Highly Pt-like electrocatalytic activity of transition metal nitrides for dyesensitized solar cells," Energy and Environmental Science, vol. 4, no. 5, pp. 1680-1683, 2011.

[16] Q. W. Jiang, G. R. Li, S. Liu, and X. P. Gao, "Surface-nitrided nickel with bifunctional structure as low-cost counter electrode for dye-sensitized solar cells," The Journal of Physical Chemistry C, vol. 114, no. 31, pp. 13397-13401, 2010.

[17] X. Lin, M. Wu, Y. Wang, A. Hagfeldt, and T. Ma, "Novel counter electrode catalysts of niobium oxides supersede Pt for dyesensitized solar cells," Chemical Communications, vol. 47, no. 41, pp. 11489-11491, 2011.

[18] M. Wu, Y. Wang, X. Lin et al., "Economical and effective sulfide catalysts for dye-sensitized solar cells as counter electrodes," Physical Chemistry Chemical Physics, vol. 13, no. 43, pp. 1929819301, 2011.

[19] F. Bonaccorso, L. Colombo, G. Yu et al., "Graphene, related twodimensional crystals, and hybrid systems for energy conversion and storage," Science, vol. 347, no. 6217, Article ID 1246501, 2015.

[20] A. H. Castro Neto, F. Guinea, N. M. R. Peres, K. S. Novoselov, and A. K. Geim, "The electronic properties of graphene," Reviews of Modern Physics, vol. 81, no. 1, pp. 109-162, 2009.

[21] F. Bonaccorso, A. Lombardo, T. Hasan, Z. Sun, L. Colombo, and A. C. Ferrari, "Production and processing of graphene and $2 \mathrm{~d}$ crystals," Materials Today, vol. 15, no. 12, pp. 564-589, 2012.

[22] J. D. Roy-Mayhew and I. A. Aksay, "Graphene materials and their use in dye-sensitized solar cells," Chemical Reviews, vol. 114, no. 12, pp. 6323-6348, 2014.

[23] L. Kavan, J. H. Yum, and M. Grätzel, "Optically transparent cathode for dye-sensitized solar cells based on graphene nanoplatelets," ACS Nano, vol. 5, no. 1, pp. 165-172, 2011.

[24] J. D. Roy-Mayhew, D. J. Bozym, C. Punckt, and I. A. Aksay, "Functionalized graphene as a catalytic counter electrode in dye-sensitized solar cells," ACS Nano, vol. 4, no. 10, pp. 62036211, 2010.

[25] M. H. Yeh, L. Y. Lin, J. S. Su et al., "Nanocomposite graphene/Pt electrocatalyst as economical counter electrode for dyesensitized solar cells," ChemElectroChem, vol. 1, no. 2, pp. 416425, 2014.

[26] G. Zhu, L. Pan, T. Lu, T. Xu, and Z. Sun, "Electrophoretic deposition of reduced graphene-carbon nanotubes composite films as counter electrodes of dye-sensitized solar cells," Journal of Materials Chemistry, vol. 21, no. 38, pp. 14869-14875, 2011.

[27] G. Liu, X. Li, H. Wang et al., "An efficient thiolate/disulfide redox couple based dye-sensitized solar cell with a graphene modified mesoscopic carbon counter electrode," Carbon, vol. 53, pp. 11$18,2013$.

[28] D. W. Zhang, X. D. Li, H. B. Li et al., "Graphene-based counter electrode for dye-sensitized solar cells," Carbon, vol. 49, no. 15, pp. 5382-5388, 2011.

[29] Y. Sun, Q. Wu, and G. Shi, "Graphene based new energy materials," Energy and Environmental Science, vol. 4, no. 4, pp. 1113-1132, 2011.

[30] D. R. Dreyer, S. Park, C. W. Bielawski, and R. S. Ruoff, "The chemistry of graphene oxide," Chemical Society Reviews, vol. 39, no. 1, pp. 228-240, 2010.

[31] J. Hass, W. A. De Heer, and E. H. Conrad, "The growth and morphology of epitaxial multilayer graphene," Journal of Physics Condensed Matter, vol. 20, no. 32, Article ID 323202, 2008.

[32] A. Reina, X. Jia, J. Ho et al., "Large area, few-layer graphene films on arbitrary substrates by chemical vapor deposition," Nano Letters, vol. 9, no. 1, pp. 30-35, 2009.
[33] H. Choi, H. Kim, S. Hwang, Y. Han, and M. Jeon, "Graphene counter electrodes for dye-sensitized solar cells prepared by electrophoretic deposition," Journal of Materials Chemistry, vol. 21, no. 21, pp. 7548-7551, 2011.

[34] A. Kaniyoor and S. Ramaprabhu, "Thermally exfoliated graphene based counter electrode for low cost dye sensitized solar cells," Journal of Applied Physics, vol. 109, no. 12, Article ID 124308, 2011.

[35] G. Wang, W. Xing, and S. Zhuo, "The production of polyaniline/graphene hybrids for use as a counter electrode in dyesensitized solar cells," Electrochimica Acta, vol. 66, pp. 151-157, 2012.

[36] C.-J. Liu, S.-Y. Tai, S.-W. Chou et al., "Facile synthesis of $\mathrm{MoS}_{2}$ /graphene nanocomposite with high catalytic activity toward triiodide reduction in dye-sensitized solar cells," Journal of Materials Chemistry, vol. 22, no. 39, pp. 21057-21064, 2012.

[37] J.-Y. Lin, A.-L. Su, C.-Y. Chang, K.-C. Hung, and T.-W. Lin, "Molybdenum disulfide/reduced graphene oxide-carbon nanotube hybrids as efficient catalytic materials in dye-sensitized solar cells," ChemElectroChem, vol. 2, no. 5, pp. 720-725, 2015.

[38] L. Bai, J. N. Ding, N. Y. Yuan, H. W. Hu, Y. Li, and X. Fang, " $\mathrm{Cu}_{2} \mathrm{ZnSnS}_{4}$ /graphene composites as low-cost counter electrode materials for dye-sensitized solar cells," Materials Letters, vol. 112, pp. 219-222, 2013.

[39] W. Yang, X. Xu, Z. Li et al., "Construction of efficient counter electrodes for dye-sensitized solar cells: $\mathrm{Fe}_{2} \mathrm{O}_{3}$ nanoparticles anchored onto graphene frameworks," Carbon, vol. 96, pp. 947954, 2016.

[40] Y. Y. Dou, G. R. Li, J. Song, and X. P. Gao, "Nickel phosphideembedded graphene as counter electrode for dye-sensitized solar cells," Physical Chemistry Chemical Physics, vol. 14, no. 4, pp. 1339-1342, 2012.

[41] C. Xu, J. Li, X. Wang et al., "Synthesis of hemin functionalized graphene and its application as a counter electrode in dyesensitized solar cells," Materials Chemistry and Physics, vol. 132, no. 2-3, pp. 858-864, 2012.

[42] J.-S. Lee, H.-J. Ahn, J.-C. Yoon, and J.-H. Jang, "Threedimensional nano-foam of few-layer graphene grown by CVD for DSSC," Physical Chemistry Chemical Physics, vol. 14, no. 22, pp. 7938-7943, 2012.

[43] K. Yu, Z. Wen, H. Pu et al., "Hierarchical vertically oriented graphene as a catalytic counter electrode in dye-sensitized solar cells," Journal of Materials Chemistry A, vol. 1, no. 2, pp. 188-193, 2013.

[44] H. Wang, K. Sun, F. Tao, D. J. Stacchiola, and Y. H. Hu, "3D honeycomb-like structured graphene and its high efficiency as a counter-electrode catalyst for dye-sensitized solar cells," Angewandte Chemie -International Edition, vol. 125, no. 35, pp. 9380-9384, 2013.

[45] W. Yang, X. Xu, Z. Tu et al., "Nitrogen plasma modified CVD grown graphene as counter electrodes for bifacial dye-sensitized solar cells," Electrochimica Acta, vol. 173, pp. 715-720, 2015.

[46] A. K. Chandiran, N. Tetreault, R. Humphry-Baker et al., "Subnanometer $\mathrm{Ga}_{2} \mathrm{O}_{3}$ tunnelling layer by atomic layer deposition to achieve $1.1 \mathrm{~V}$ open-circuit potential in dye-sensitized solar cells," Nano Letters, vol. 12, no. 8, pp. 3941-3947, 2012.

[47] S. M. Feldt, E. A. Gibson, E. Gabrielsson, L. Sun, G. Boschloo, and A. Hagfeldt, "Design of organic dyes and cobalt polypyridine redox mediators for high-efficiency dye-sensitized solar cells," Journal of the American Chemical Society, vol. 132, no. 46, pp. 16714-16724, 2010. 
[48] L. Kavan, J.-H. Yum, M. K. Nazeeruddin, and M. Grätzel, "Graphene nanoplatelet cathode for Co(III)/(II) mediated dyesensitized solar cells," ACS Nano, vol. 5, no. 11, pp. 9171-9178, 2011.

[49] T. Daeneke, A. J. Mozer, T.-H. Kwon et al., "Dye regeneration and charge recombination in dye-sensitized solar cells with ferrocene derivatives as redox mediators," Energy \& Environmental Science, vol. 5, no. 5, pp. 7090-7099, 2012.

[50] L. Kavan, J.-H. Yum, and M. Graetzel, "Optically transparent cathode for $\mathrm{Co}$ (III/II) mediated dye-sensitized solar cells based on graphene oxide," ACS Applied Materials and Interfaces, vol. 4, no. 12, pp. 6999-7006, 2012.

[51] C.-T. Hsieh, B.-H. Yang, and Y.-F. Chen, "Dye-sensitized solar cells equipped with graphene-based counter electrodes with different oxidation levels," Diamond and Related Materials, vol. 27-28, pp. 68-75, 2012.

[52] L. Kavan, J.-H. Yum, and M. Grätzel, "Graphene nanoplatelets outperforming platinum as the electrocatalyst in co-bipyridinemediated dye-sensitized solar cells," Nano Letters, vol. 11, no. 12, pp. 5501-5506, 2011.

[53] P. Zhai, C.-C. Lee, Y.-H. Chang, C. Liu, T.-C. Wei, and S.-P. Feng, "A significant improvement in the electrocatalytic stability of N-doped graphene nanosheets used as a counter electrode for $\left[\mathrm{Co}(\text { bpy })_{3}\right]^{3+/ 2+}$ based porphyrin-sensitized solar cells," ACS Applied Materials and Interfaces, vol. 7, no. 3, pp. 2116-2123, 2015.

[54] R. Bajpai, S. Roy, P. Kumar et al., "Graphene supported platinum nanoparticle counter-electrode for enhanced performance of dye-sensitized solar cells," ACS Applied Materials \& Interfaces, vol. 3, no. 10, pp. 3884-3889, 2011.

[55] L. Wan, Q. Zhang, S. Wang et al., "A two-step reduction method for synthesizing graphene nanocomposites with a low loading of well-dispersed platinum nanoparticles for use as counter electrodes in dye-sensitized solar cells," Journal of Materials Science, vol. 50, no. 12, pp. 4412-4421, 2015.

[56] M.-Y. Yen, C.-C. Teng, M.-C. Hsiao et al., "Platinum nanoparticles/graphene composite catalyst as a novel composite counter electrode for high performance dye-sensitized solar cells," Journal of Materials Chemistry, vol. 21, no. 34, pp. 12880-12888, 2011.

[57] Y.-G. Kim, Z. A. Akbar, D. Y. Kim, S. M. Jo, and S.-Y. Jang, "Aqueous dispersible graphene/Pt nanohybrids by green chemistry: application as cathodes for dye-sensitized solar cells," ACS Applied Materials \& Interfaces, vol. 5, no. 6, pp. 2053-2061, 2013.

[58] V.-D. Dao, N. T. Q. Hoa, L. L. Larina, J.-K. Lee, and H.-S. Choi, "Graphene-platinum nanohybrid as a robust and lowcost counter electrode for dye-sensitized solar cells," Nanoscale, vol. 5, no. 24, pp. 12237-12244, 2013.

[59] H. Choi, H. Kim, S. Hwang, M. Kang, D.-W. Jung, and M. Jeon, "Electrochemical electrodes of graphene-based carbon nanotubes grown by chemical vapor deposition," Scripta Materialia, vol. 64, no. 7, pp. 601-604, 2011.

[60] S. Li, Y. Luo, W. Lv et al., "Vertically aligned carbon nanotubes grown on graphene paper as electrodes in lithium-ion batteries and dye-sensitized solar cells," Advanced Energy Materials, vol. 1, no. 4, pp. 486-490, 2011.

[61] H. Choi, H. Kim, S. Hwang, W. Choi, and M. Jeon, "Dyesensitized solar cells using graphene-based carbon nano composite as counter electrode," Solar Energy Materials and Solar Cells, vol. 95, pp. 323-325, 2011.

[62] H. Kim, H. Choi, S. Hwang, Y. Kim, and M. Jeon, "Fabrication and characterization of carbon-based counter electrodes prepared by electrophoretic deposition for dye-sensitized solar cells," Nanoscale Research Letters, vol. 7, no. 1, article 53, 2012.

[63] L.-L. Shao, M. Chen, T.-Z. Ren, and Z.-Y. Yuan, "Ordered mesoporous carbon/graphene nano-sheets composites as counter electrodes in dye-sensitized solar cells," Journal of Power Sources, vol. 274, pp. 791-798, 2015.

[64] W. Sun, T. Peng, Y. Liu, N. Huang, S. Guo, and X. Zhao, "Ordered mesoporous carbon-decorated reduced graphene oxide as efficient counter electrode for dye-sensitized solar cells," Carbon, vol. 77, pp. 18-24, 2014.

[65] T. Battumur, S. H. Mujawar, Q. T. Truong et al., "Graphene/ carbon nanotubes composites as a counter electrode for dyesensitized solar cells," Current Applied Physics, vol. 12, no. 1, pp. e49-e53, 2012.

[66] X. Miao, K. Pan, Q. Pan et al., "Highly crystalline graphene/ carbon black composite counter electrodes with controllable content: synthesis, characterization and application in dyesensitized solar cells," Electrochimica Acta, vol. 96, pp. 155-163, 2013.

[67] J. Velten, A. J. Mozer, D. Li et al., "Carbon nanotube/graphene nanocomposite as efficient counter electrodes in dye-sensitized solar cells," Nanotechnology, vol. 23, no. 8, Article ID 085201, 2012.

[68] M. Stefik, J.-H. Yum, Y. Hu, and M. Grätzel, "Carbon-graphene nanocomposite cathodes for improved Co (II/III) mediated dye-sensitized solar cells," Journal of Materials Chemistry A, vol. 1, pp. 4982-4987, 2013.

[69] L.-H. Chang, C.-K. Hsieh, M.-C. Hsiao et al., "A graphenemulti-walled carbon nanotube hybrid supported on fluorinated tin oxide as a counter electrode of dye-sensitized solar cells," Journal of Power Sources, vol. 222, pp. 518-525, 2013.

[70] J. Ma, W. Shen, C. Li, and F. Yu, "Light reharvesting and enhanced efficiency of dye-sensitized solar cells based 3DCNT/graphene counter electrodes," Journal of Materials Chemistry A, vol. 3, no. 23, pp. 12307-12313, 2015.

[71] J. Ma, C. Li, F. Yu, and J. Chen, “'Brick-like’ N-doped graphene/ carbon nanotube structure forming three-dimensional films as high performance metal-free counter electrodes in dyesensitized solar cells," Journal of Power Sources, vol. 273, pp. 1048-1055, 2015.

[72] W. Hong, Y. Xu, G. Lu, C. Li, and G. Shi, “Transparent graphene/ PEDOT-PSS composite films as counter electrodes of dyesensitized solar cells," Electrochemistry Communications, vol. 10, no. 10, pp. 1555-1558, 2008.

[73] K. S. Lee, Y. Lee, J. Y. Lee, J.-H. Ahn, and J. H. Park, "Flexible and platinum-free dye-sensitized solar cells with conductingpolymer-coated graphene counter electrodes," ChemSusChem, vol. 5, no. 2, pp. 379-382, 2012.

[74] G. Yue, J. Wu, Y. Xiao et al., "Functionalized graphene/poly(3,4ethylenedioxythiophene):polystyrenesulfonate as counter electrode catalyst for dye-sensitized solar cells," Energy, vol. 54, pp. 315-321, 2013.

[75] B. He, Q. Tang, M. Wang, C. Ma, and S. Yuan, "Complexation of polyaniline and graphene for efficient counter electrodes in dyesensitized solar cells: enhanced charge transfer ability," Journal of Power Sources, vol. 256, pp. 8-13, 2014.

[76] Y.-S. Wang, S.-M. Li, S.-T. Hsiao et al., "Thickness-selfcontrolled synthesis of porous transparent polyaniline-reduced graphene oxide composites towards advanced bifacial dyesensitized solar cells," Journal of Power Sources, vol. 260, pp. 326-337, 2014. 
[77] W. Liu, Y. Fang, P. Xu et al., "Two-step electrochemical synthesis of polypyrrole/reduced graphene oxide composites as efficient pt-free counter electrode for plastic dye-sensitized solar cells," ACS Applied Materials and Interfaces, vol. 6, no. 18, pp. 1624916256, 2014.

[78] S. Das, P. Sudhagar, S. Nagarajan et al., "Synthesis of grapheneCoS electro-catalytic electrodes for dye sensitized solar cells," Carbon, vol. 50, no. 13, pp. 4815-4821, 2012.

[79] H. Bi, W. Zhao, S. Sun et al., "Graphene films decorated with metal sulfide nanoparticles for use as counter electrodes of dyesensitized solar cells," Carbon, vol. 61, pp. 116-123, 2013.

[80] X. Duan, Z. Gao, J. Chang et al., "CoS ${ }_{2}$-graphene composite as efficient catalytic counter electrode for dye-sensitized solar cell," Electrochimica Acta, vol. 114, pp. 173-179, 2013.

[81] E. Bi, H. Chen, X. Yang, W. Peng, M. Grätzel, and L. Han, "A quasi core-shell nitrogen-doped graphene/cobalt sulfide conductive catalyst for highly efficient dye-sensitized solar cells," Energy \& Environmental Science, vol. 7, no. 8, pp. 26372641, 2014.

[82] L. Sun, Y. Bai, N. Zhang, and K. Sun, "The facile preparation of a cobalt disulfide-reduced graphene oxide composite film as an efficient counter electrode for dye-sensitized solar cells," Chemical Communications, vol. 51, no. 10, pp. 1846-1849, 2015.

[83] X. Miao, K. Pan, G. Wang et al., "Well-dispersed cos nanoparticles on a functionalized graphene nanosheet surface: a counter electrode of dye-sensitized solar cells," Chemistry-A European Journal, vol. 20, no. 2, pp. 474-482, 2014.

[84] J. Huo, J. Wu, M. Zheng, Y. Tu, and Z. Lan, "High performance sponge-like cobalt sulfide/reduced graphene oxide hybrid counter electrode for dye-sensitized solar cells," Journal of Power Sources, vol. 293, pp. 570-576, 2015.

[85] Z. Li, F. Gong, G. Zhou, and Z.-S. Wang, " $\mathrm{NiS}_{2} /$ reduced graphene oxide nanocomposites for efficient dye-sensitized solar cells," The Journal of Physical Chemistry C, vol. 117, no. 13, pp. 6561-6566, 2013.

[86] X. Zuo, R. Zhang, B. Yang et al., "NiS nanoparticles anchored on reduced graphene oxide to enhance the performance of dyesensitized solar cells," Journal of Materials Science: Materials in Electronics, vol. 26, no. 10, pp. 8176-8181, 2015.

[87] J. Shen, R. Cheng, Y. Luo et al., "Growth of NiS/graphene nanocomposites for enhanced performance of dye sensitized solar cells," Journal of Solid State Electrochemistry, vol. 19, no. 4, pp. 1045-1052, 2015.

[88] G. Yue, J.-Y. Lin, S.-Y. Tai, Y. Xiao, and J. Wu, "A catalytic composite film of $\mathrm{MoS}_{2}$ /graphene flake as a counter electrode for Pt-free dye-sensitized solar cells," Electrochimica Acta, vol. 85, pp. 162-168, 2012.

[89] J.-Y. Lin, C.-Y. Chan, and S.-W. Chou, "Electrophoretic deposition of transparent $\mathrm{MoS}_{2}$-graphene nanosheet composite films as counter electrodes in dye-sensitized solar cells," Chemical Communications, vol. 49, no. 14, pp. 1440-1442, 2013.

[90] J.-Y. Lin, G. Yue, S.-Y. Tai et al., "Hydrothermal synthesis of graphene flake embedded nanosheet-like molybdenum sulfide hybrids as counter electrode catalysts for dye-sensitized solar cells," Materials Chemistry and Physics, vol. 143, no. 1, pp. 53-59, 2013.

[91] B. Yang, X. Zuo, P. Chen et al., "Nanocomposite of tin sulfide nanoparticles with reduced graphene oxide in high-efficiency dye-sensitized solar cells," ACS Applied Materials \& Interfaces, vol. 7, no. 1, pp. 137-143, 2015.

[92] B. Yang, P. Chen, X. Zuo et al., "Structural phase transition from tin (IV) sulfide to tin (II) sulfide and the enhanced performance by introducing graphene in dye-sensitized solar cells," Electrochimica Acta, vol. 176, pp. 797-803, 2015.

[93] G. Li, X. Chen, and G. Gao, " $\mathrm{Bi}_{2} \mathrm{~S}_{3}$ microspheres grown on graphene sheets as low-cost counter-electrode materials for dye-sensitized solar cells," Nanoscale, vol. 6, no. 6, pp. 32833288, 2014.

[94] E. Bi, Y. Su, H. Chen et al., "A hybrid catalyst composed of reduced graphene oxide/ $\mathrm{Cu}_{2} \mathrm{~S}$ quantum dots as a transparent counter electrode for dye sensitized solar cells," RSC Advances, vol. 5, no. 12, pp. 9075-9078, 2015.

[95] L. Zhou, J. Luo, X. Yang et al., "Graphene-wrapped CuInS composites for efficient dye-sensitized solar cells," Functional Materials Letters, vol. 8, no. 1, Article ID 1550011, 2015.

[96] M. Liu, G. Li, and X. Chen, "One-pot controlled synthesis of spongelike $\mathrm{CuInS}_{2}$ microspheres for efficient counter electrode with graphene assistance in dye-sensitized solar cells," ACS Applied Materials \& Interfaces, vol. 6, no. 4, pp. 2604-2610, 2014.

[97] R. Bajpai, S. Roy, N. Koratkar, and D. S. Misra, "NiO nanoparticles deposited on graphene platelets as a cost-effective counter electrode in a dye sensitized solar cell," Carbon, vol. 56, pp. 5663, 2013.

[98] V.-D. Dao, L. L. Larina, K.-D. Jung, J.-K. Lee, and H.-S. Choi, "Graphene-NiO nanohybrid prepared by dry plasma reduction as a low-cost counter electrode material for dye-sensitized solar cells," Nanoscale, vol. 6, no. 1, pp. 477-482, 2014.

[99] F. Gong, Z. Li, H. Wang, and Z.-S. Wang, "Enhanced electrocatalytic performance of graphene via incorporation of $\mathrm{SiO}_{2}$ nanoparticles for dye-sensitized solar cells," Journal of Materials Chemistry, vol. 22, no. 33, pp. 17321-17327, 2012.

[100] Q. Chang, Z. Ma, J. Wang et al., “Graphene nanosheets@ZnO nanorods as three-dimensional high efficient counter electrodes for dye sensitized solar cells," Electrochimica Acta, vol. 151, pp. 459-466, 2015.

[101] Q. Zhang, Y. Liu, Y. Duan et al., " $\mathrm{Mn}_{3} \mathrm{O}_{4}$ /graphene composite as counter electrode in dye-sensitized solar cells," RSC Advances, vol. 4, no. 29, pp. 15091-15097, 2014.

[102] K. Xiong, G. Li, C. Jin, and S. Jin, " $\mathrm{La}_{0.65} \mathrm{Sr}_{0.35} \mathrm{MnO}_{3} @ \mathrm{RGO}$ nanocomposites as an effective counter electrode for dyesensitized solar cells," Materials Letters, vol. 164, pp. 609-612, 2016.

[103] F. Gong, H. Wang, and Z.-S. Wang, "Self-assembled monolayer of graphene/Pt as counter electrode for efficient dye-sensitized solar cell," Physical Chemistry Chemical Physics, vol. 13, no. 39, pp. 17676-17682, 2011.

[104] G. Yue, J. Wu, Y. Xiao et al., "Platinum/graphene hybrid film as a counter electrode for dye-sensitized solar cells," Electrochimica Acta, vol. 92, pp. 64-70, 2013.

[105] K. Saranya, N. Sivasankar, and A. Subramania, "Microwaveassisted exfoliation method to develop platinum-decorated graphene nanosheets as a low cost counter electrode for dyesensitized solar cells," RSC Advances, vol. 4, no. 68, pp. 3622636233, 2014.

[106] C.-T. Hsieh, B.-H. Yang, and J.-Y. Lin, "One- and twodimensional carbon nanomaterials as counter electrodes for dye-sensitized solar cells," Carbon, vol. 49, no. 9, pp. 3092-3097, 2011.

[107] G. Wang, W. Xing, and S. Zhuo, "Application of mesoporous carbon to counter electrode for dye-sensitized solar cells," Journal of Power Sources, vol. 194, no. 1, pp. 568-573, 2009.

[108] H. Sun, D. Qin, S. Huang et al., "Dye-sensitized solar cells with $\mathrm{NiS}$ counter electrodes electrodeposited by a potential reversal 
technique," Energy \& Environmental Science, vol. 4, no. 8, pp. 2630-2637, 2011.

[109] F. Gong, H. Wang, X. Xu, G. Zhou, and Z.-S. Wang, "In situ growth of $\mathrm{Co}_{0.85} \mathrm{Se}$ and $\mathrm{Ni}_{0.85} \mathrm{Se}$ on conductive substrates as high-performance counter electrodes for dye-sensitized solar cells," Journal of the American Chemical Society, vol. 134, no. 26, pp. 10953-10958, 2012.

[110] J. S. Jang, D. J. Ham, E. Ramasamy, J. Lee, and J. S. Lee, "Platinum-free tungsten carbides as an efficient counter electrode for dye sensitized solar cells," Chemical Communications, vol. 46, no. 45, pp. 8600-8602, 2010.

[111] G. R. Li, F. Wang, J. Song, F. Y. Xiong, and X. P. Gao, “TiNconductive carbon black composite as counter electrode for dye-sensitized solar cells," Electrochimica Acta, vol. 65, pp. 216220, 2012.

[112] B. Lei, G. R. Li, and X. P. Gao, "Morphology dependence of molybdenum disulfide transparent counter electrode in dyesensitized solar cells," Journal of Materials Chemistry A, vol. 2, no. 11, pp. 3919-3925, 2014.

[113] L. J. Brennan, M. T. Byrne, M. Bari, and Y. K. Gun'ko, "Carbon nanomaterials for dye-sensitized solar cell applications: a bright future," Advanced Energy Materials, vol. 1, no. 4, pp. 472-485, 2011.

[114] S. Das, P. Sudhagar, V. Verma et al., "Amplifying charge-transfer characteristics of graphene for triiodide reduction in dyesensitized solar cells," Advanced Functional Materials, vol. 21, no. 19, pp. 3729-3736, 2011.

[115] X. Zhang, Y. Yang, S. Guo, F. Hu, and L. Liu, "Mesoporous $\mathrm{Ni}_{0.85}$ Se nanospheres grown in situ on graphene with high performance in dye-sensitized solar cells," ACS Applied Materials \& Interfaces, vol. 7, no. 16, pp. 8457-8464, 2015.

[116] D. Yu, E. Nagelli, F. Du, and L. Dai, "Metal-free carbon nanomaterials become more active than metal catalysts and last longer," The Journal of Physical Chemistry Letters, vol. 1, no. 14, pp. 2165-2173, 2010.

[117] J. Balamurugan, T. D. Thanh, N. H. Kim, and J. H. Lee, "Nitrogen-doped graphene nanosheets with FeN core-shell nanoparticles as high-performance counter electrode materials for dye-sensitized solar cells," Advanced Materials Interfaces, vol. 3, no. 1, Article ID 1500348, 2016. 

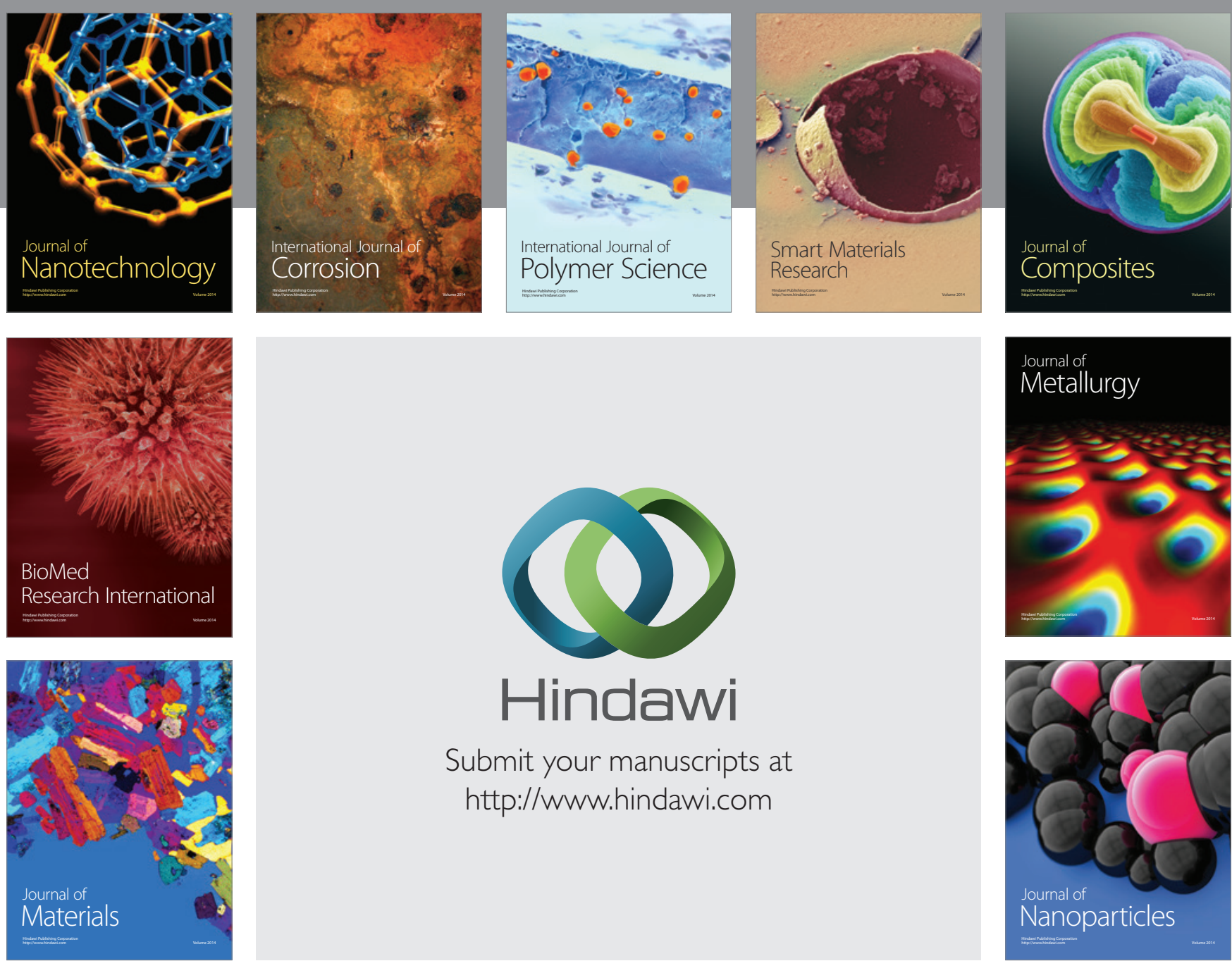

\section{Hindawi}

Submit your manuscripts at

http://www.hindawi.com

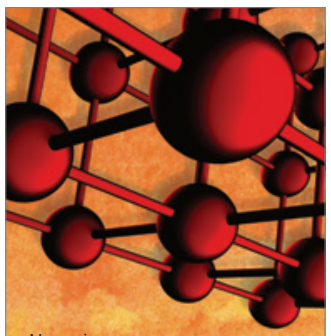

Materials Science and Engineering
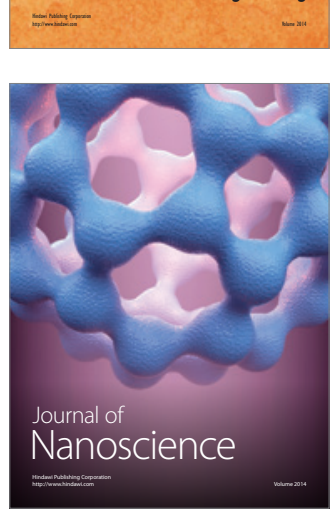
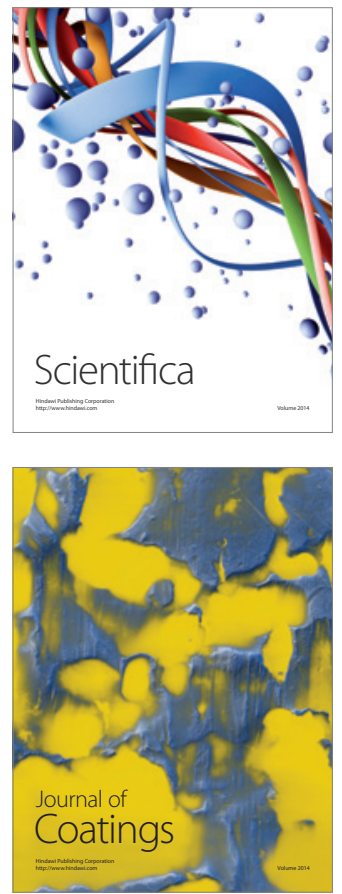
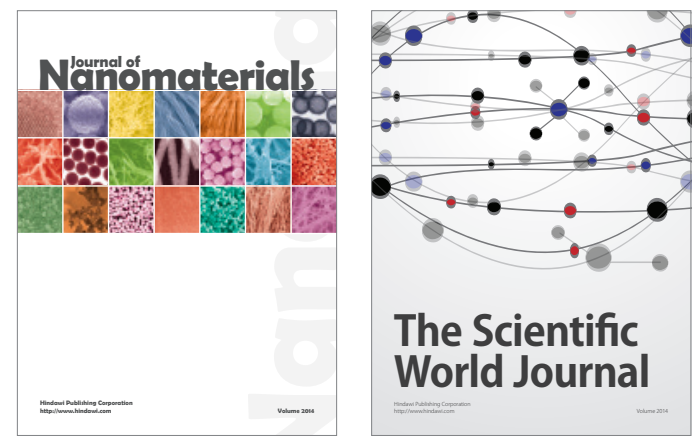

The Scientific World Journal
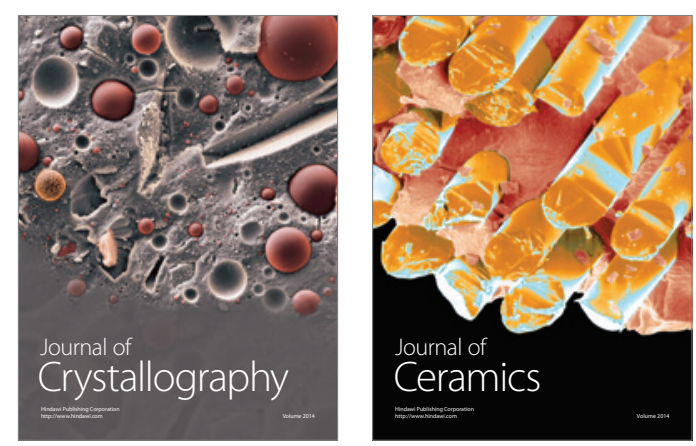
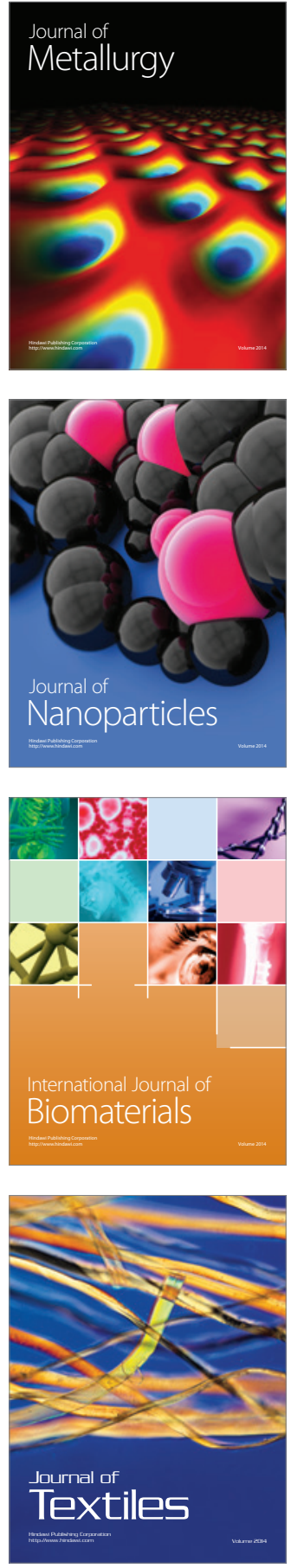